Provided for non-commercial research and education use. Not for reproduction, distribution or commercial use.

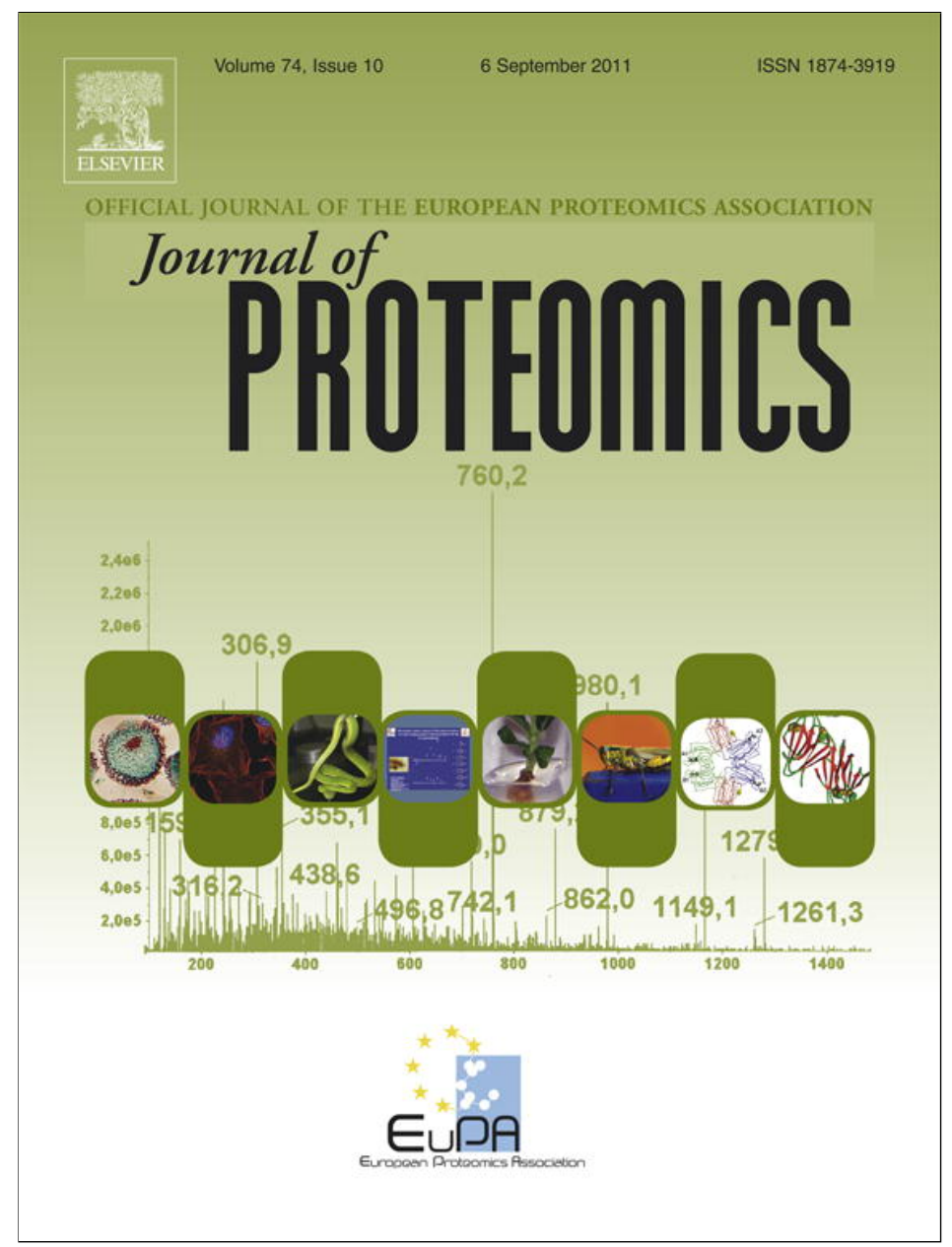

This article appeared in a journal published by Elsevier. The attached copy is furnished to the author for internal non-commercial research and education use, including for instruction at the authors institution and sharing with colleagues.

Other uses, including reproduction and distribution, or selling or licensing copies, or posting to personal, institutional or third party websites are prohibited.

In most cases authors are permitted to post their version of the article (e.g. in Word or Tex form) to their personal website or institutional repository. Authors requiring further information regarding Elsevier's archiving and manuscript policies are encouraged to visit:

http://www.elsevier.com/copyright 


\title{
Response to biotic and oxidative stress in Arabidopsis thaliana: Analysis of variably phosphorylated proteins
}

\author{
Chao Huang $^{a, 1}$, Francesca Verrillo ${ }^{b, 1}$, Giovanni Renzone ${ }^{c}$, Simona Arena ${ }^{c}$, \\ Mariapina Rocco ${ }^{b}$, Andrea Scaloni ${ }^{\mathrm{c}, *}$, Mauro Marra ${ }^{a, * *}$ \\ a Department of Biology, University of Rome "Tor Vergata", Rome, Italy \\ ${ }^{\mathrm{b}}$ Department of Biological and Environmental Sciences, University of Sannio, Benevento, Italy \\ c Proteomics \& Mass Spectrometry Laboratory, ISPAAM, National Research Council, Naples, Italy
}

\section{A R T I C L E I N F O}

Article history:

Received 8 November 2010

Accepted 9 May 2011

Available online 15 May 2011

\section{Keywords:}

Plant defence

Elicitors

Proteomics

Phosphoproteins

\begin{abstract}
A B S T R A C T
Protein phosphorylation plays a pivotal role in the regulation of many cellular events; increasing evidences indicate that this post-translational modification is involved in plant response to various abiotic and biotic stresses. Since phosphorylated proteins may be present at low abundance, enrichment methods are generally required for their analysis. We here describe the quantitative changes of phosphoproteins present in Arabidopsis thaliana leaves after challenging with elicitors or treatments mimicking biotic stresses, which stimulate basal resistance responses, or oxidative stress. Phosphoproteins from elicited and control plants were enriched by means of metal oxide affinity chromatography and resolved by 2D electrophoresis. A comparison of the resulting proteomic maps highlighted phosphoproteins showing quantitative variations induced by elicitor treatment; these components were identified by MALDI-TOF peptide mass fingerprinting and/or nanoLCESI-LIT-MS/MS experiments. In total, 97 differential spots, representing 75 unique candidate phosphoproteins, were characterized. They are representative of different protein functional groups, such as energy and carbon metabolism, response to oxidative and abiotic stresses, defense, protein synthesis, RNA processing and cell signaling. Ascertained protein phosphorylation found a positive confirmation in available Arabidopsis phosphoproteome database. The role of each identified phosphoprotein is here discussed in relation to plant defense mechanisms. Our results suggest a partial overlapping of the responses to different treatments, as well as a communication with key cellular functions by imposed stresses.
\end{abstract}

(c) 2011 Elsevier B.V. All rights reserved.

\section{Introduction}

Plants are in intimate contact with the environment; they are constantly being challenged by unfavourable environmental conditions (excess/lack of water, light, nutrients or tempera- ture extremes) and other organisms eventually causing physical damages (insects or herbivores) or disease development (pathogenic bacteria and fungi). In order to protect themselves from biotic stresses, plants have evolved different lines of defence mechanisms, which are often partly

* Correspondence to: A. Scaloni, Proteomics \& Mass Spectrometry Laboratory, ISPAAM, National Research Council, via Argine 1085, 80147 Naples, Italy.

** Correspondence to: M. Marra, Department of Biology, University of Rome “Tor Vergata”, via della Ricerca Scientifica 1, 00133 Rome, Italy.

E-mail addresses: andrea.scaloni@ispaam.cnr.it (A. Scaloni), Mauro.Marra@uniroma2.it (M. Marra).

${ }^{1}$ These authors gave an equal contribution to this work. 
overlapped [1]. Usually, recognition of elicitor molecules from pathogens, or Pathogen-Associated Molecular Patterns (PAMPs), triggers a plant basal defence that is non-specific and confers a broad-spectrum resistance [2,3]. Pathogens must circumvent or suppress this first-line surveillance mechanism in order to develop disease. On the other hand, some plant varieties also express a mechanism known as gene-for-gene resistance [4], which relies on the recognition of specific avirulence gene products from the pathogen by complementary $\mathrm{R}$ receptors. This recognition elicits a set of biochemical reactions, including generation of $\mathrm{H}_{2} \mathrm{O}_{2}$ and reactive oxygen species (ROS), lipid peroxidation, ion fluxes, protein phosphorylation and phytoalexin synthesis, which are generally referred to as the Hypersensitive Response (HR) [5]. This response eventually leads to programmed death of infected cells, thereby restricting the favourable environment to pathogens and arresting infection progression. Local response can also generate signals systemically triggering enhanced resistance to secondary infections (SAR) or directed to plant organs not yet colonised by the pathogen [6]. Although different pathways exist for sensing and responding to different environmental cues, the occurrence of cross-tolerance [7], a phenomenon where the exposure to a particular stress also increases the resistance to other ones, suggests that underlying cellular responses may share common mechanisms, at least in part. ROS production and consequent alteration of the plant cell redox balance, for instance, is associated with diverse biotic and abiotic stimuli, such as wounding, fungi challenge or excess-light damage. Response to pathogens underlies a complex reprogramming of plant metabolism, which represents an unnecessary use of cell resources in the absence of pathogen challenge. Plants, although intrinsically inferior to constitutive defences, have evolved inducible mechanisms. In this context, protein phosphorylation is a crucial event for regulation of many processes essential for plant biochemistry and physiology. Increasing evidence indicates that this post-translational modification plays a pivotal role also at different stages of plant response to pathogens, such as signal transduction events, control of the cellular redox status, adjustments to metabolism and accumulation of defense molecules [8]. However, systematic knowledge about in vivo plant protein phosphorylation in response to pathogen stimuli is lacking. Recently, functional genomic studies (including proteomics) have greatly contributed to the molecular dissection of plant pathogen interactions, allowing to identify a number of defense-related candidate proteins and helping to clarify specific gene expression patterns [9]. In this respect, the study of sub-proteomes has been greatly recommended to improve technical sensitivity/resolution and reduce the overall system complexity.

In this work, we report on the main quantitative changes of phosphorylated proteins within Arabidopsis thaliana leaves as result of its challenge with various elicitors or treatment mimicking different biotic stresses, which stimulate basal resistance responses, or oxidative stress. In particular, plant leaves were treated with i) chitosan, a cell wall component of many fungi able to induce oxidative burst and defense proteins synthesis [10]; ii) benzothiadiazole, a compound known to activate a number of SAR-associated genes and leading to enhanced plant protection against various pathogens [11]; iii) mechanical injury/wounding, mimicking physical damage by insects/herbivores and known to induce the transcription of wound-responsive genes [12]; iv) methyl viologen (MV), a powerful inducer of oxidative stress, known to be a component of the defense responses [13]. Thus, phosphorylated proteins were enriched by Metal Oxide Affinity Chromatography (MOAC), resolved by 2-DE and resulting proteomic patterns were compared. Differently modified components were identified by various MS approaches; their function is discussed according to previous data on defense responses.

\section{Materials and methods}

\subsection{Plant growth and stress treatments}

Arabidopsis thaliana ecotype Columbia (Col-0) was grown in a growth chamber at $22^{\circ} \mathrm{C}$, under a $16 \mathrm{~h}$ light/ $8 \mathrm{~h}$ dark cycle. Threeweek old plants were subjected to treatment with elicitors as follows: i) chitosan: a solution containing $300 \mu \mathrm{g} / \mathrm{mL}$ chitosan from crab shell (Sigma), which was previously hydrolyzed according to Hadwiger and Beckman [14]; ii) benzothiadiazole: a solution containing $0.4 \mathrm{~g} / \mathrm{L}$ Bion 50 WG (Syngenta); iii) methyl viologen: a solution containing $50 \mu \mathrm{M}$ methyl viologen (Sigma). In all cases, elicitor solutions also contained $0.1 \% \mathrm{w} / \mathrm{v}$ Tween 20 and were sprayed on leaves to ensure its complete wetting (about $2 \mathrm{~mL}$ for each plant). Aqueous $0.1 \% \mathrm{w} / \mathrm{v}$ Tween 20 spraying was used for control plants. Wounding of rosette leaves was done by piercing small holes through all of the leaf blades to be harvested. Leaves were harvested after a treatment for $8 \mathrm{~h}$.

\subsection{Hydrogen peroxide assay}

To measure $\mathrm{H}_{2} \mathrm{O}_{2}$ produced in challenged leaves, the method by Bellincampi et al. [15] was used. Five explant rectangles $(2 \times 4 \mathrm{~mm}$ for each sample) with the midrib medially placed, were excised from control or treated leaves and incubated in deionised water under vacuum for $2 \mathrm{~min}$ and then at ambient pressure, for $30 \mathrm{~min}$. Samples were centrifuged at $10,000 \times \mathrm{g}$, for 5 min, and then the supernatant was used for $\mathrm{H}_{2} \mathrm{O}_{2}$ determination. Supernatant $(500 \mu \mathrm{L})$ was added to $500 \mu \mathrm{l}$ of the assay reagent $(500 \mathrm{mM}$ ammonium ferrous sulphate, $50 \mathrm{mM}$ sulphuric acid, $200 \mu \mathrm{M}$ xylenol orange, $200 \mathrm{mM}$ sorbitol); the absorbance of the $\mathrm{Fe}^{3+}$-xylenol complex at $560 \mathrm{~nm}$ was then determined after incubation for $45 \mathrm{~min}$.

\subsection{Protein extraction}

Protein mining was performed according to the phenol extraction method [16], with minor modifications. Briefly, three-weeks old rosette Arabidopsis leaves were finely powdered in liquid $\mathrm{N}_{2}$ using a mortar and dried under vacuum. One $g$ of dried leaves was suspended in $20 \mathrm{~mL}$ of ice-cold extraction buffer $(700 \mathrm{mM}$ sucrose, 500 mM Tris-HCl pH 7.5, 50 mM EDTA, 100 mM KCl, 2\% $\mathrm{w} / \mathrm{v} \beta$-mercaptoethanol, $1 \mathrm{mM}$ PMSF, 1\% w/v PVP, 0.25\% w/v CHAPS, $40 \mathrm{mM} \mathrm{NaF}, 1 \mu \mathrm{M}$ okadaic acid). After addition of an equal volume of phenol saturated-500 mM Tris-HCl, pH 7.5, the mixture was stirred for $5 \mathrm{~min}$ in Waring blender and then centrifuged at $10,000 \times \mathrm{g}$ for $10 \mathrm{~min}$, at $4{ }^{\circ} \mathrm{C}$. The upper phenol phase was removed and extracted once with the extraction buffer. Proteins were precipitated from the phenol phase by 
addition of $5 \mathrm{vol}$ of saturated ammonium acetate in methanol, overnight at $-20^{\circ} \mathrm{C}$. Precipitated proteins were centrifuged at $10,000 \times \mathrm{g}$, for $30 \mathrm{~min}$. Proteins were stored at $-80^{\circ} \mathrm{C}$, until used. Three biological replicates for each treatment were analyzed, which were then subjected to an independent phenol extraction and subsequent proteomic analysis.

\subsection{Metal oxide affinity chromatography}

MOAC was performed according to Rohrig et al. [17]. Eighty mg of phenol-precipitated proteins were suspended in $30 \mathrm{~mL}$ of incubation buffer (30 mM MES pH 6.1, 0.1 M sodium glutamate, $0.1 \mathrm{M}$ potassium aspartate, $0.25 \% \mathrm{w} / \mathrm{v}$ CHAPS, $8 \mathrm{M}$ urea), sonicated and incubated overnight, under magnetic stirring, at $4{ }^{\circ} \mathrm{C}$. After incubation, the suspension was sonicated again and then centrifuged at $15,000 \times \mathrm{g}$, for $15 \mathrm{~min}$. The supernatant was collected and added to $2 \mathrm{~g}$ of $\mathrm{Al}(\mathrm{OH})_{3}$ previously washed twice with incubation buffer. After incubation on a rotating mixer for $2 \mathrm{~h}$, at $8^{\circ} \mathrm{C}$, the matrix was recovered by centrifugation at $6000 \times \mathrm{g}$ for $10 \mathrm{~min}$ and washed four times with $15 \mathrm{~mL}$ of $30 \mathrm{mM}$ MES $\mathrm{pH}$ 6.1, $0.15 \mathrm{M}$ sodium glutamate, $0.15 \mathrm{M}$ potassium aspartate, $0.25 \% \mathrm{w} / \mathrm{v}$ CHAPS, $8 \mathrm{M}$ urea. Bound proteins were eluted with $20 \mathrm{~mL}$ of $200 \mathrm{mM}$ potassium pyrophosphate, $8 \mathrm{M}$ urea, $\mathrm{pH}$ 9, for $60 \mathrm{~min}$, at room temperature. After centrifugation at $6,000 \times g$ for $10 \mathrm{~min}$, the supernatant was collected and $0.01 \mathrm{vol}$ of $2 \% \mathrm{w} / \mathrm{v}$ sodium deoxycholate and $0.1 \mathrm{vol}$ of $100 \% \mathrm{w} / \mathrm{v}$ TCA were added. Precipitated proteins were recovered in a single tube by stepwise centrifugation at $14,000 \times \mathrm{g}$, for $10 \mathrm{~min}$. Final pellet was washed with $25 \% \mathrm{w} / \mathrm{v}$ TCA, suspended in Tris- $\mathrm{HCl}$ buffer $\mathrm{pH} 7.5$ containing $80 \%$ acetone and finally washed with ice-cold acetone. The pellet was dried under reduced pressure and stored at $-80^{\circ} \mathrm{C}$ until used. Protein samples before and after MOAC were analyzed by SDS-PAGE; gels were stained with Pro-Q Diamond (Invitrogen) to reveal phosphorylated proteins and SyproRuby (Invitrogen) to detect total proteins, according to manufacturer's instructions. Fluorescent dyes were visualised using a VersaDoc 4000 scanner (Bio-Rad).

\subsection{2-D electrophoresis and gel image acquisition}

Protein pellets were dissolved in IEF buffer ( $9 \mathrm{M}$ urea, $4 \% \mathrm{w} / \mathrm{v}$ CHAPS, 0.5\% v/v Triton X-100, $20 \mathrm{mM} \mathrm{DTT,} \mathrm{1 \%} \mathrm{w/v} \mathrm{Bio-Rad}$ carrier ampholytes $\mathrm{pH}$ 3-10). Protein concentration was estimated by using the Bradford assay, modified according to Ramagli and Rodriguez [18]. IPG strips (17 cm pH 4-7, Bio-Rad ReadyStrip, Bio-Rad) were rehydrated overnight with $300 \mu \mathrm{L}$ of IEF buffer containing $300 \mu \mathrm{g}$ of total proteins. Proteins were focused using a Protean IEF Cell (Bio-Rad) at $12^{\circ} \mathrm{C}$, by applying the following voltages: $250 \mathrm{~V}(90 \mathrm{~min}), 500 \mathrm{~V}(90 \mathrm{~min}), 1000 \mathrm{~V}$ (180 min) and $8000 \mathrm{~V}$ for a total of $52 \mathrm{KVh}$ [16]. After focusing, the proteins were reduced by incubating the IPG strips with $1 \%$ $\mathrm{w} / \mathrm{v}$ DTT in $10 \mathrm{~mL}$ of equilibration buffer $(50 \mathrm{mM}$ Tris- $\mathrm{HCl} \mathrm{pH}$ $8.8,6 \mathrm{M}$ urea, $30 \% \mathrm{w} / \mathrm{v}$ glycerol, $2 \% \mathrm{w} / \mathrm{v}$ SDS and a dash of bromophenol blue) for $15 \mathrm{~min}$, and alkylated with $2.5 \% \mathrm{w} / \mathrm{v}$ iodoacetamide in $10 \mathrm{~mL}$ of equilibration buffer for $15 \mathrm{~min}$. Electrophoresis in the second dimension was carried out on $12 \%$ polyacrylamide gels $(180 \times 240 \times 1 \mathrm{~mm})$ with a Protean apparatus (Bio-Rad), using electrophoresis buffer (25 mM Tris$\mathrm{HCl} \mathrm{pH} \mathrm{8.3,} \mathrm{1.92} \mathrm{M} \mathrm{glycine} \mathrm{and} \mathrm{1 \%} \mathrm{w/v} \mathrm{SDS),} \mathrm{with} 120 \mathrm{~V}$ applied for $12 \mathrm{~h}$, until the dye front reached the bottom of the gel. 2-DE gels were stained with colloidal Coomassie G250 and/or Pro-Q Diamond to detect total and phosphorylated proteins, respectively; resulting images were acquired by using GS-800 and/or VersaDoc 4000 imaging systems (Bio-Rad). For quantitative analysis, each sample was analyzed in triplicate.

\subsection{Gel image analysis}

Digitized images of Coomassie-stained gels were analyzed by using the PDQuest (ver 7.4) 2-D analysis software (Bio-Rad), which allowed spot detection, landmarks identification, aligning/matching of spots within gels, quantification of matched spots and their analysis, according to manufacturer's instructions. Manual inspection of the spots was performed to verify the accuracy of automatic gel matching; any errors in the automatic procedure were manually corrected prior to the final data analysis. The spot volume was used as the analysis parameter for quantifying protein expression. The protein spot volume was normalized to the spot volume of the entire gel (i.e., of all the protein spots). Fold changes in protein spot levels were calculated between spot volumes in the treated group relative to that in the control gels. Statistically significant changes in protein amount were determined by using two sequential data analysis criteria. First, a protein spot had to be present in all gels for each sample to be included in the analysis. Next, statistically significant changes in amount were determined by using the distribution of fold-change values in the data. Spots were determined to be statistically significant if the difference between the average intensity of a specific protein spot in the control and treated plants (three technical replicates of three biological samples) was greater than one standard deviation of the spot intensities for both groups. An absolute two-fold change in normalized spot densities was then considered indicative of a differentially modified protein; values $>2$ or $<0.5$ were associated with increased or decreased phosphoprotein amounts after treatment, respectively.

\subsection{Protein digestion and MS analysis}

Spots from 2-DE were manually excised from gels, minced and washed with water. Proteins were in-gel reduced, S-alkylated and digested with trypsin, as previously reported [19]. Protein digests were subjected to a desalting/concentration step on ZipTipC18 pipette tips (Millipore Corp., Bedford, MA, USA) before MALDI-TOF-MS and/or nanoLC-ESI-LIT-MS/MS analysis.

During MALDI-TOF peptide mass fingerprinting (PMF) experiments, peptide mixtures were loaded on the instrument target together with CHCA as matrix, using the dried droplet technique. Samples were analysed with a Voyager-DE PRO mass spectrometer (Applied Biosystems, USA). Peptide mass spectra were acquired in reflectron mode; internal mass calibration was performed with peptides derived from trypsin autoproteolysis. Data were elaborated using the DataExplorer 5.1 software (Applied Biosystems). PSD fragment ion spectral analysis of the most abundant mass signal within each MALDI-TOF-MS spectrum was performed as previously reported [20].

Peptide mixtures were eventually analyzed by nanoLC-ESILIT-MS/MS using a LTQ XL mass spectrometer (ThermoFinnigan, USA) equipped with Proxeon nanospray source connected to an Easy-nanoLC (Proxeon, Denmark) [21]. Peptide mixtures were 
separated on an Easy $\mathrm{C}_{18}$ column $(10 \times 0.075 \mathrm{~mm}, 3 \mu \mathrm{m})$ (Proxeon) using a gradient of acetonitrile containing $0.1 \%$ formic acid in aqueous $0.1 \%$ formic acid; acetonitrile ramped from $5 \%$ to $35 \%$ over $15 \mathrm{~min}$ and from $35 \%$ to $95 \%$ over $2 \mathrm{~min}$, at a flow rate of $300 \mathrm{~nL} / \mathrm{min}$. Spectra were acquired in the range $\mathrm{m} / \mathrm{z}$ 400-2000. Acquisition was controlled by a data-dependent product ion scanning procedure over the three most abundant ions, enabling dynamic exclusion (repeat count 2 and exclusion duration $1 \mathrm{~min})$. The mass isolation window and collision energy were set to $\mathrm{m} / \mathrm{z} 3$ and $35 \%$, respectively.

\subsection{Protein identification}

MASCOT software package version 2.2.06 (Matrix Science, UK) [22] was used to identify spots unambiguously from an updated plant non-redundant sequence database (NCBI nr 2009/05/03). MALDI-TOF PMF data were searched using a mass tolerance value of $40-80 \mathrm{ppm}$, trypsin as proteolytic enzyme, a missed cleavages maximum value of 2 and Cys carbamidomethylation and Met oxidation as fixed and variable modification, respectively. NanoLC-ESI-LIT-MS/MS data were searched by using a mass tolerance value of $2 \mathrm{Da}$ for precursor ion and $0.8 \mathrm{Da}$ for MS/MS fragments, trypsin as proteolytic enzyme, a missed cleavages maximum value of 2 and Cys carbamidomethylation and Met oxidation as fixed and variable modification, respectively. MALDI-TOF PMF candidates with a cumulative MASCOT score $>83$, which were also confirmed by PSD data, or nanoLCESI-LIT-MS/MS candidates with more than 2 assigned peptides with an individual MASCOT score $>25$, both corresponding to $\mathrm{p}<0.05$ for a significant identification, were further evaluated by the comparison with their calculated mass and pI values, using the experimental values obtained from 2-DE.

\section{Results and discussion}

\subsection{Induction of $\mathrm{H}_{2} \mathrm{O}_{2}$ production}

Since accumulated evidence indicates that hydrogen peroxide is a key signalling molecule involved in plant response to both biotic and abiotic stresses [23], the time-course of $\mathrm{H}_{2} \mathrm{O}_{2}$ production in challenged Arabidopsis leaves was followed to test the effectiveness of administration of elicitors or wounding treatment. Control plants were analyzed for comparison. Results demonstrated that benzothiadiazole, chitosan, methyl viologen or wounding stimuli were able to trigger $\mathrm{H}_{2} \mathrm{O}_{2}$ production in leaves, even though with partly different time courses (Fig. 1). However, $\mathrm{H}_{2} \mathrm{O}_{2}$ levels after $8 \mathrm{~h}$ were comparable among all treatments; then this time was chosen for comparative proteomic analysis.

\subsection{MOAC purification of phosphorylated proteins}

Arabidopsis leaf tissues from plants treated with chitosan, benzothiadiazole, wounding, methyl viologen or control were used for the purification of phosphorylated proteins. After $8 \mathrm{~h}$-treatments, total proteins were extracted and phosphoproteins enriched by using a MOAC procedure [17]. Input loads and eluted fractions were analysed by SDS-PAGE; gels were stained with the aspecific fluorescent dye SyproRuby

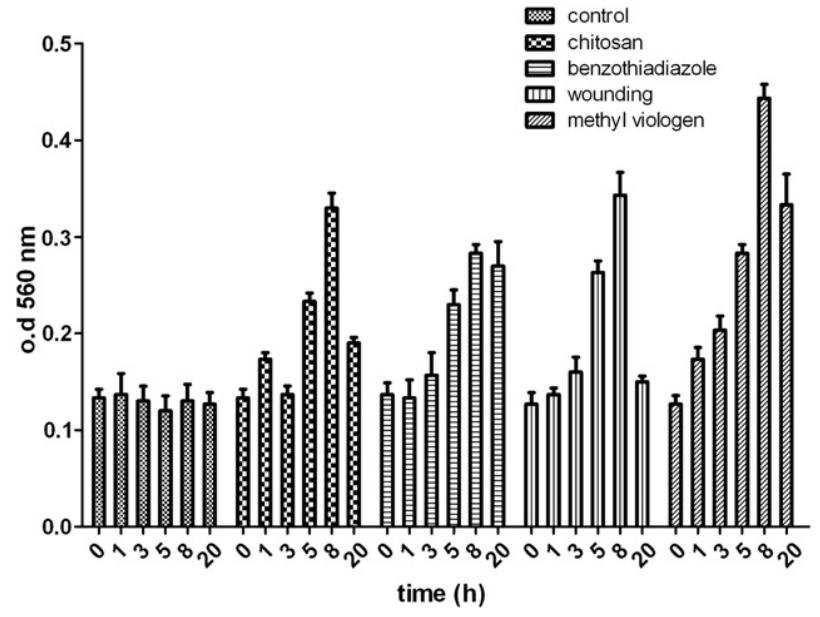

Fig. 1 - Time-course of $\mathrm{H}_{2} \mathrm{O}_{2}$ production in A. thaliana leaves after challenge with elicitors of plant basal defence (chitosan and benzothiadiazole), an inducer of oxidative stress (methyl viologen) or mechanical injury (wounding). At the indicated times after elicitor treatments or wounding, explants from leaves were taken and processed as reported in the experimental section. The release of $\mathrm{H}_{2} \mathrm{O}_{2}$ in the incubation medium was then determined by measuring the absorbance value of the corresponding $\mathrm{Fe}^{3+}$-xylenol complex at $560 \mathrm{~nm}$. Reported values are the mean of three independent experiments from different samples with standard errors.

(Fig. 2A) or the phosphoproteins-specific fluorescent reagent Pro-Q Diamond (Fig. 2B). Results demonstrated that MOAC efficiently enriched phosphoproteins from total leaf extracts.

3.3. Proteomic analysis of elicitor-treated leaves identifies differentially phosphorylated proteins

A proteomic approach was then used to identify candidate phosphoproteins whose abundance changed upon stimulus exerted by various elicitors of plant basal defence. MOACenriched proteins from control and challenged leaves were then resolved by 2-D electrophoresis within the $\mathrm{pH}$ range 4-7 and mass range $10-200 \mathrm{kDa}$. Representative gel images obtained after staining with colloidal Coomassie G250 and Pro-Q Diamond (Fig. 3A and B) confirmed optimal enrichment of phosphoproteins within samples.

To ascertain quantitative changes in relative spot densities for elicitor-treated leaves compared to control, colloidal Coomassie-stained gels were subjected to comparative software-assisted image analysis (Fig. 3C-D)(Supporting Information Table S1). Average proteomic maps showed 285 (untreated), 250 (chitosan), 270 (benzothiadiazole), 262 (wounding) and 300 (methyl viologen) spots, with a degree of similarity for the different treatments (compared to the control) of 81,86 , 89 , and $77 \%$ respectively. Statistical evaluation $(p<0.05)$ of relative spot densities allowed to detect spots differentially modified in challenged leaves with at least a two-fold increase or decrease, when compared to control leaves. In total, 97 differential spots were detected between treated and control plants, among which 29, 27, 24 and 30 after chitosan, benzothiadiazole, wounding and methyl viologen treatment, respectively. 


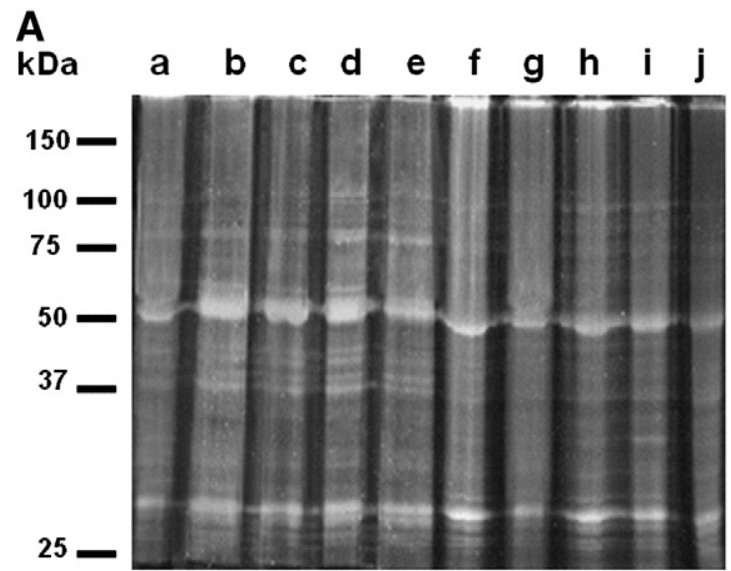

B

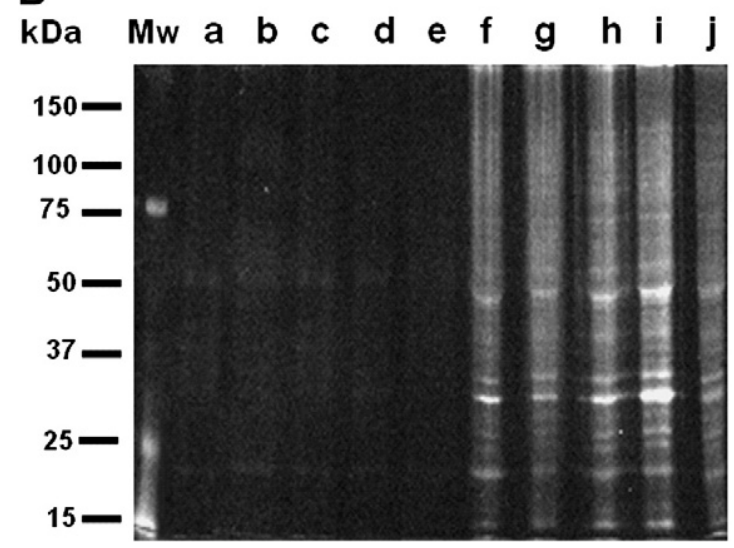

Fig. 2 - SDS-PAGE of total proteins or MOAC-purified phosphoproteins from $A$. thaliana leaves after challenge with elicitors of plant basal defence (chitosan and benzothiadiazole), an inducer of oxidative stress (methyl viologen) or mechanical injury (wounding). Panel A. SyproRuby staining. Lanes a to e: total proteins $(5 \mu \mathrm{g})$ from control, wounding, chitosan, benzothiadiazole and methyl viologen-treated plants, respectively; lanes $\mathrm{f}$ to $\mathrm{j}$ : phosphoproteins $(5 \mu \mathrm{g})$ eluted from MOAC corresponding to control, wounding, chitosan, benzothiadiazole and methyl viologen-treated plants, respectively. Panel B. Pro-Q Diamond staining specific for phosphoproteins. Lanes a to $\mathrm{j}$ as in Panel A. Mw, molecular mass markers).

These spots were excised from gels, proteolyzed, subjected to MS analysis and database searching for protein assignment. Nineteen identification derived from MALDI-TOF PMF data, 77 from nanoLC-ESI-LIT-MS/MS data and 5 from gel matching. Identified protein species, together with their quantitative variations as result of the different treatments, are reported in Table 1. All proteins, except three, have been previously described in recent large-scale phosphoproteome studies as being phosphorylated [8,24-31]. Information on protein phosphorylation was deduced by searching Arabidopsis phosphoproteome RIPP$\mathrm{DB}$, PhosPhAt and P3DB database, available on the WEB at the following addresses: https://phosphoproteome.psc.database. riken.jp, http://phosphat.mpimp-golm.mpg.de/phosphat.html and http://digbio.missouri.edu/p3db/download, respectively. Most of the spots contained a single protein component, which will be discussed below in a dedicated section for each treatment. Those spots containing multiple species ( 6 in number), for which it was not possible to determine that one responsible for quantitative changes in differential experiments, will be not described. No identification was obtained for spots 30, 62, 64 and 67. In general, a classification according to functional data showed that a large portion of the proteins differentially modified in challenged leaves belong to broad classes involved in: i) energy production and carbon metabolism; ii) response to environmental and biotic stresses; iii) RNA transport and processing; iv) protein synthesis; v) cellular signaling.

\subsubsection{Chitosan treatment}

Chitosan administration to leaves determined a reduced amount of phosphoproteins involved in energy/carbon metabolism. In fact, ribulose bisphosphate carboxylase/oxygenase (RuBisCO) activase (spots 1-3) appeared strongly down-regulated following treatment. This protein is known to be phosphorylated on Ser/Thr/Tyr residues and modified by 5 '-phospho-DNA [32]; the occurrence of multiple protein spots was associated with its modification degree. Its molecular target, namely ribulose carboxylase/oxygenase large subunit (spot 12), was also downregulated. This phosphorylated protein has been already reported to be enriched by MOAC procedures [17]. Other enzymes involved in carbon metabolism, namely cysteine synthase (spot 16), mitochondrial NAD-dependent malate dehydrogenase (spot 15), a probable chloroplastic isoform of fructose bisphosphate aldolase (At2g21330) (spot 10) and glyceraldehyde-3-phosphate dehydrogenase (GAPDH) subunit A (spots 13 and 14), also resulted down-regulated. The role of their phosphorylated isoforms is not known at present, although in some cases it may be related to a functional regulation of enzyme activity or turn-over. In Arabidopsis, for example, it has been shown that GAPDH proteolysis is modulated by binding to regulatory 14-3-3 proteins, through protein phosphorylation [33]. In plants, a cytosolic nonphosphorylating GAPDH is occurring in addition to glycolitic GAPDH; this phosphorylated enzyme is involved in the generation of NADPH and is modulated by oxidative stress [34]. Proteins belonging to the photosynthetic apparatus, namely two components of the photosystem II oxygenevolving complex (spots 4 and 5), a component of the cytochrome $b_{6}-f$ complex (spot 9 ) and an extrinsic protein associated to the PS II complex (spot 7), also showed lower levels of their phosphorylated species.

In contrast, phosphoproteins involved in stress and defense responses, RNA transport/processing and protein synthesis generally showed increased levels after chitosan administration. In particular, two phospho-isoforms of the heat shock cognate $70 \mathrm{kDa}$ protein 3 (HSC70-3) (spots 23 and 24) and a phosphorylated heat shock protein 70-like component (spot 27) resulted strongly up-regulated. The heat shock protein 70 family (HSP70) contains both heat-inducible and constitutively expressed members, named heat shock cognate proteins (HSC70), which are involved in protein targeting and degradation [35]. Arabidopsis genome encodes for five different cytosolic HSC70s, among which three are expressed constitutively (HSC70-1, 2 and 3); interestingly, expression of all genes is increased after environmental stresses [35]. Recently, a specific interaction of HSC70-3 with turnip mosaic virus RNA-dependent RNA polymerase has 

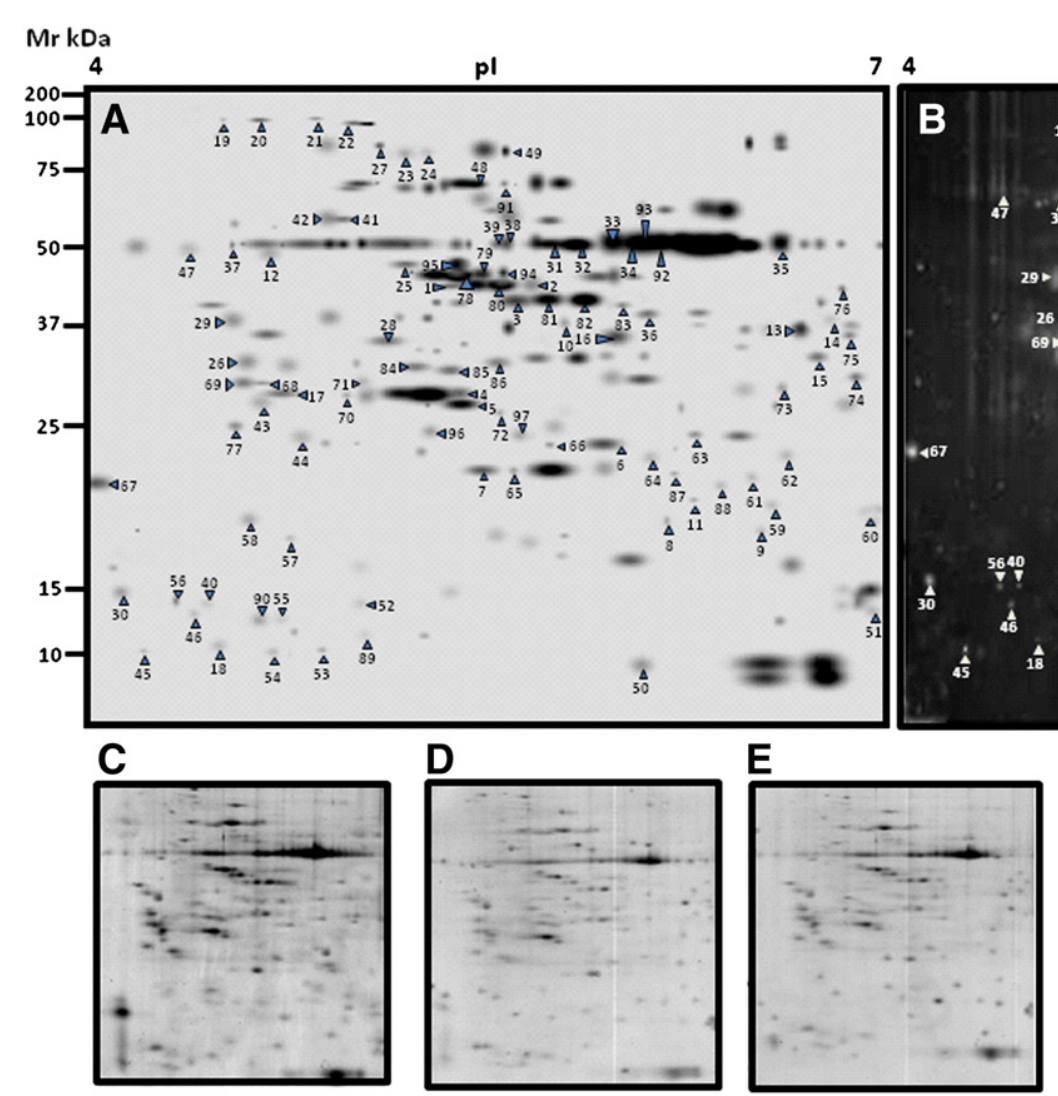

pl 7
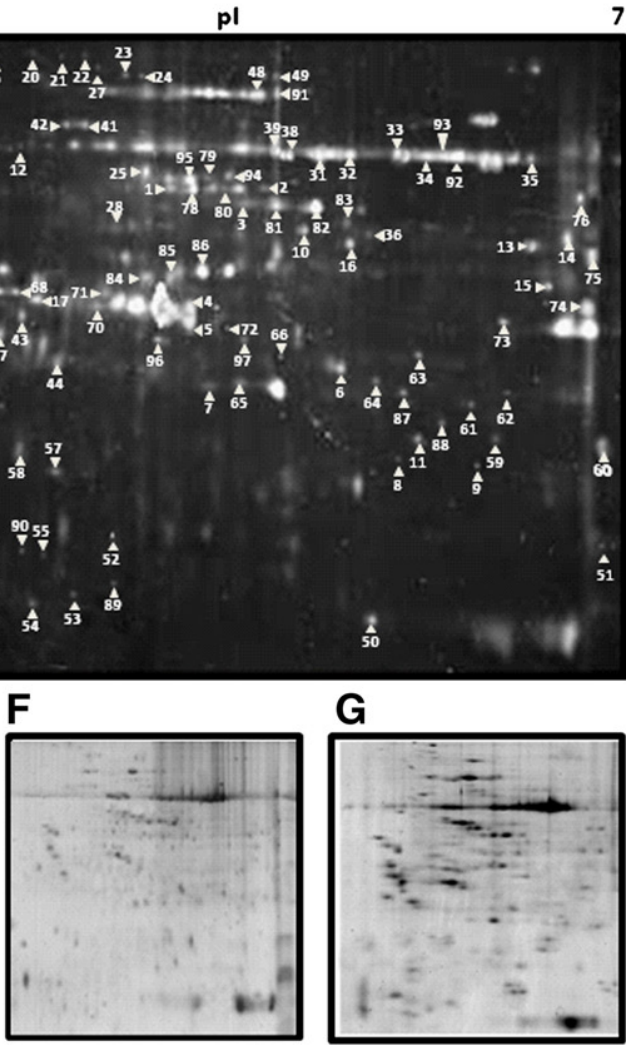

Fig. 3 - 2D proteomic maps of phosphoproteins purified by MOAC from A. thaliana leaves after challenge with elicitors of plant basal defence (chitosan and benzothiadiazole), an inducer of oxidative stress (methyl viologen) or mechanical injury (wounding). Panels A and B. Master gel stained with colloidal Coomassie G250 or Pro-Q Diamond to detect total and phosphorylated proteins, respectively; numbers in both gels indicate proteins showing quantitative differences, which were further identified by MS approaches (Table 1). Panels C to G; representative Coomassie G250-stained gels of phosphoproteins from control and chitosan, benzothiadiazole, wounding and methyl viologen treatments. Proteins purified by MOAC were separated in first dimension by using $18 \mathrm{~cm}$ IPG strips ( $\mathrm{pH}$ 4-7 linear); second dimension was performed on a vertical slab gel $(12 \% \mathrm{~T})$, as reported in the experimental section.

been reported [36], suggesting a role of this heat shock cognate protein in pathogenesis.

Two phosphoproteins whose function has been related to RNA processing/transport, namely RNA-binding protein cp33 (spot 26) and Ran-binding protein 1 (spot 28), showed higher modification levels in chitosan-treated samples. The first protein belongs to a family of chloroplast ribonucleoproteins involved in RNA metabolism, which are now emerging as multifunctional regulatory proteins [37]; a member of this class is involved in antioxidative defense in Arabidopsis [38]. The second one is a small GTP-binding protein essential for the export of mRNA/ribonucleoprotein complexes from nucleus [39]. Nuclear RNA export is an emerging research topic in abiotic stress response of plants; it is worth noting that specific $\mathrm{mRNA} /$ microRNA export under stress conditions is mediated by karyopherins through a Ran-GTPase-dependent pathway [40]. On the other hand, the progesterone-binding protein homolog Atmp2 (spot 17) showed moderately-increased levels upon treatment. This cytochrome $b_{5}$ heme- and steroid-binding domains-containing phosphoprotein, present in thylacoid membrane, has been reported being involved in oxidative defense and stress response [41]. Phosphorylated proteasome
RPT5a subunit (spot 25) showed a 5-fold increase; this protein belongs to the AAA-ATPases associated with the proteasome regulatory particle [42]. Recently, Hatsugai and coworkers have demonstrated the involvement of proteasome-dependent tonoplast and plasma membrane fusion in a novel plant defense process triggering bacteria-induced programmed cell death, which leads to a vacuolar release of antimicrobial and deathinducing compounds [43]. Phosphorylated patellin-1 (spot 22) also showed a 7-fold up-regulation. This protein belongs to a small family of Sec14 and GOLD domains-containing lipidbinding proteins probably involved in membrane-trafficking events [44]; phosphoproteomic studies on membrane fractions of salt-stressed Arabidopsis demonstrated that patellin2 phosphorylation levels raise upon stress [28]. Phosphorylated fibrillin-3 (spot 29) also showed increased levels. Fibrillins are thylakoid-associated proteins involved in protection from photo-oxidative damage, which are also known to accumulate in response to different abiotic/biotic stress conditions [45]. Remarkably, a differential phosphoproteomic study on Arabidopsis after Pseudomonas syringae challenge led to the identification of phosphorylated fibrillin as a component of plant basal defense response [46]. Finally, three spots 
related to unknown (spot 19) or putative (spots 20 and 21) proteins showed augmented levels. For the first one (Atg322240), transcriptomic data available from the plant-microbe interaction database (http://www.phi-base.org) indicate its strong induction upon inoculation with bacterial pathogens or elicitors.

\subsubsection{Benzothiadiazole treatment}

Benzothiadiazole treatment determined a variable amount of phosphoproteins involved in energy production/carbon metabolism and up-regulation of components related to stress/defense response. In the first case, multiple phosphorylated isoforms of ribulose 1,5-bisphosphate carboxylase/oxygenase (spots 31, 33, 34, 35, 39 and 47) resulted up-regulated. A similar trend was also observed for mitochondrial NADH ubiquinone dehydrogenase subunit 5 (spot 45), which was the one showing the largest increase following treatment. Conversely, some ATP synthases showed increased (ATPase $\beta$ subunit-spot 37) or decreased (ATPase CF1 $\beta$ subunit—spot 32) levels after elicitor treatment.

As far as protein involved in stress response and defense, three heat shock phosphoproteins resulted up-regulated, namely the $70 \mathrm{kDa}$ heat shock cognate protein 3 (HSC70) (spot 24), Hsp 70-like protein (spot 27) and luminal-binding protein (spot 48). For the first two proteins, a similar trend was also observed following chitosan treatment. Other phosphoproteins involved in stress and defense response were highly up-regulated, namely fibrillin-3 (spot 29), the progesteronebinding protein homolog Atmp2 (spot 17) and protein disulfideisomerase 1 (spot 41). Remarkably, the first two phosphorylated proteins were also identified as strongly induced after chitosan challenge, while the latter was up-regulated in Arabidopsis leaves following wounding (see below).

Other phosphoproteins that do not classify in the abovementioned categories were late embryogenesis abundant protein (spot 42) and cell division control protein homolog A (spot 49); they showed augmented amounts after treatment. Moreover, spots 20 and 21 were associated with an Arabidopsis protein of unknown function, which also resulted up-regulated by chitosan treatment. Also in this case, its abundance was highly increased by elicitor treatment.

\subsubsection{Wounding}

Leave wounding determined an increased amount of phosphoproteins involved in energy production/carbon metabolism and down-regulation of phosphorylated components related to RNA metabolism. In the first case, multiple phosphorylated isoforms of RuBisCO activase (spots 2, 3, 78, 79, 80, 81 and 82) resulted upregulated. A similar condition occurred for phosphorylated cytosolic triosephosphate isomerase (spot 97), glutamine synthetase (spots 94 and 95) and two forms of putative enolase (At2g36530) (spots 92 and 93). Mutations at LOS2 locus, which encodes for a bifunctional enolase, have been reported to impair freezing tolerance in Arabidopsis [47]. In contrast, phosphorylated cytochrome $b_{6}-f$ complex Fe-S subunit (spot 88) and glycine cleavage system $H$ protein 1 (spot 90), involved in photorespiration, showed a reduced modification.

Among the class of stress response and defense proteins, increased levels were observed for phosphorylated disulfide-isomerase A6 (spot 83), which is an highly conserved protein in eukaryotic cells; it is located in endoplasmic reticulum
(ER), where preserves compartment homeostasis through a mechanism referred to as unfolded protein response [48], and is implicated in seed development and pathogen response [49]. Conversely, phosphorylated luminal-binding protein 1 and 2 (spot 91) levels appeared decreased. These proteins function as ER-located chaperones. Arabidopsis genome contains three luminal-binding protein genes, among which one lacks the ER retention motif and has been detected in the cell wall, where it probably plays a different function [50].

Some proteins whose function is related to RNA binding/ transport/processing were identified, namely phosphorylated Ran-binding protein 1 (spot 28) and putative chloroplast RNAbinding protein (spots 84 and 85 ); their abundance diminished in wounded leaves. Levels of the first protein have been also reported to increase in chitosan-challenged leaves. Other proteins that do not classify in the categories mentioned above are a $16.5 \mathrm{kDa}$ thylakoidal protein with unknown function (spot 89), putative uncharacterized protein At1g55480 (spot 86), nascent polypeptide-associated complex subunit $\alpha$-like protein 2 (spot 77) and BTF3 transcription factor (spot 87). Whereas levels of the two former proteins were decreased, those of the remaining ones were increased upon wounding. Nascent polypeptideassociated complex subunit $\alpha$-like protein has been shown to be a phosphorylated salt-stress responsive protein in rice roots [51].

\subsubsection{Methyl viologen treatment}

Methy viologen administration to leaves determined an increased amount of phosphoproteins involved in: i) carbon metabolism, such as ribulose bisphosphate carboxylase small chain $1 \mathrm{~B}$ and $1 \mathrm{~A}$ (spot 50) and triosephospate isomerase (spot 66); ii) energy production, such as mitochondrial NADH ubiquinone dehydrogenase subunit 5 (spot 57), mitochondrial glycine cleavage system $\mathrm{H}$ protein 1 (spot 55), mitochondrial malate dehydrogenase (MDH) (spot 15); iii) some thylacoidal enzymes, such as cytochrome $b_{6}-\mathrm{f}$ complex Fe-S subunit (spot 59), oxygen-evolving enhancer proteins 2-1 (spot 65) and 1-2 (spot 72) [29] and $\mathrm{H}^{+}$-transporting ATP synthase chain 9 (spot 53). MDH (At1g53240) plays a key role in the tricarboxylic-acid pathway, glycolysis, gluconeogenesis and lipid metabolism. It has been shown that MDH levels are augmented in salt-stressed Arabidopsis roots [52] and following oxidative stress induced by jasmonic acid [53]. On the other hand, experiments on plants deficient in photorespiratory enzymes, such as those belonging to the glycine cleavage system, have demonstrated that these proteins are associated with protection from oxidative damage and resistance to diseases [54]. Photorespiration has a significant impact upon glutathione levels, which in turn are necessary to fuel the ascorbate-glutathione cycle for ROS detoxification. Proteomic studies on Arabidopsis response to bacterial challenge classified $\mathrm{H}^{+}$-ATPase (At4g32260) as a PAMPresponsive protein associated to basal defense [46].

Another group of up-regulated phosphoproteins after MV treatment was represented by enzymes involved in protection from abiotic/oxidative stress, namely cytosolic ascorbate peroxidase 1 (APX1) (spot 63), thioredoxin M-type 4 (spot 52) and peptydil-prolyl cis-trans isomerase (spot 73). APXs are main enzymes responsible for $\mathrm{H}_{2} \mathrm{O}_{2}$ removal in plant cytosol, mitochondria and chloroplasts [55]. Previous studies showed that APX1 is a central component of the reactive gene network in Arabidopsis [56]. In oxygenic photosynthetic organisms, 


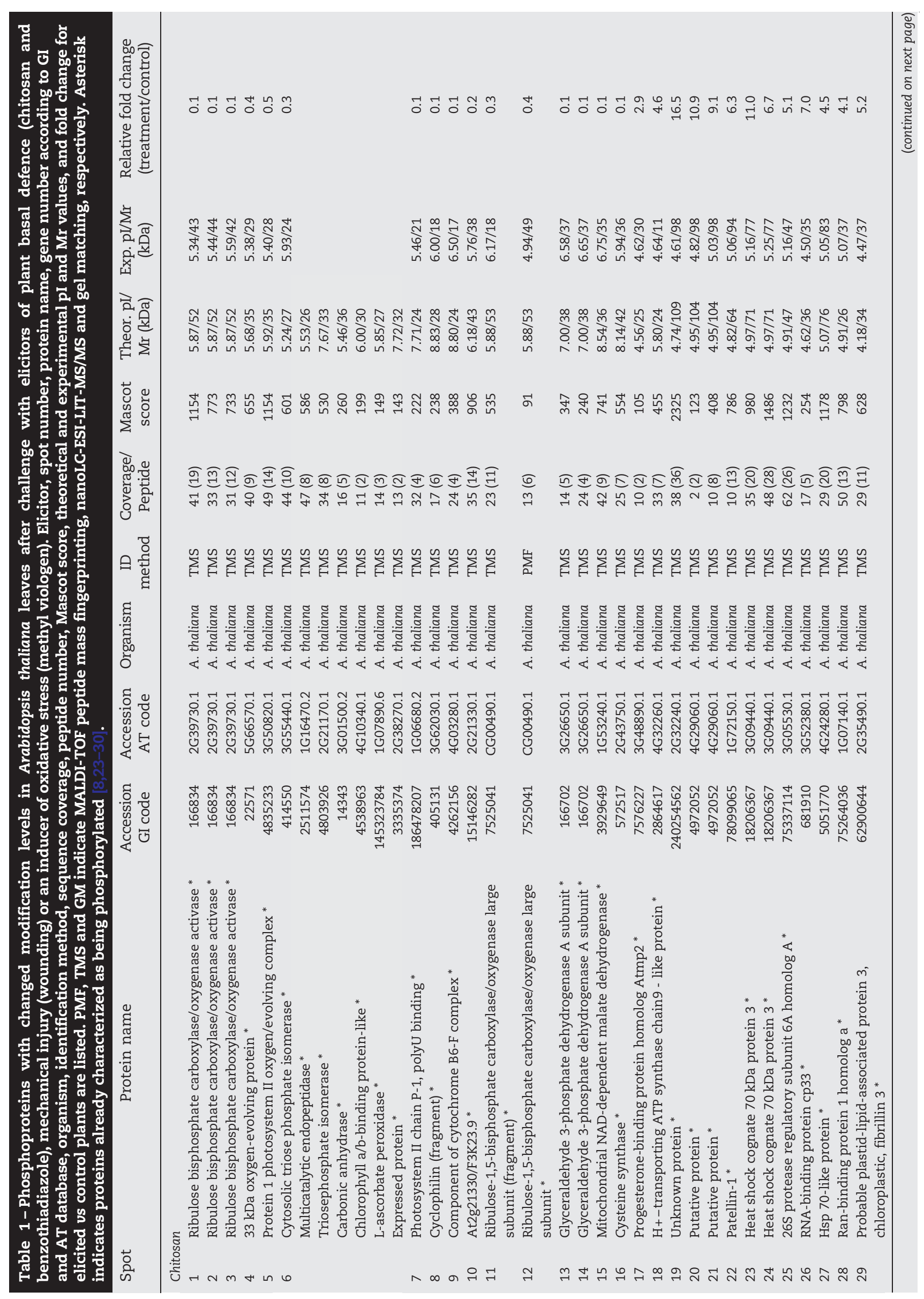




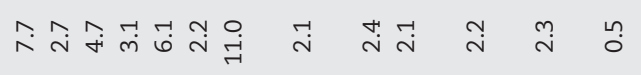

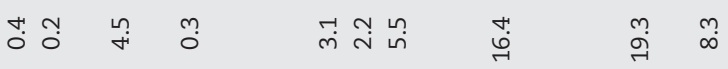

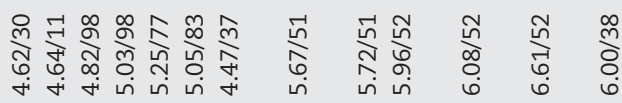

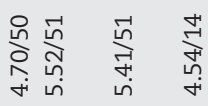

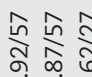

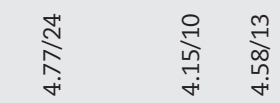

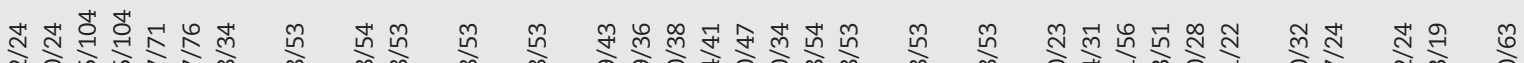

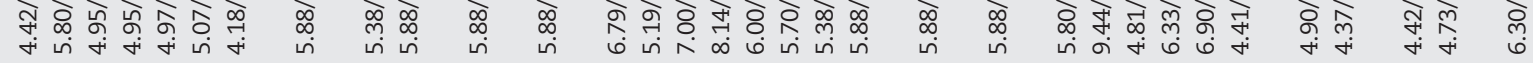

兽学

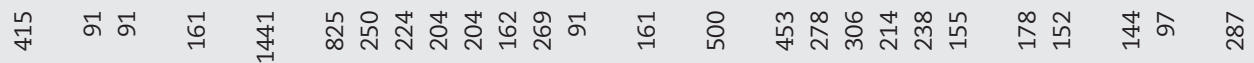

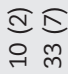

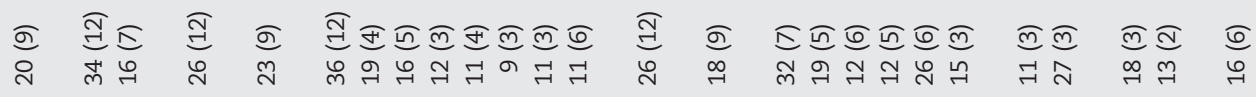

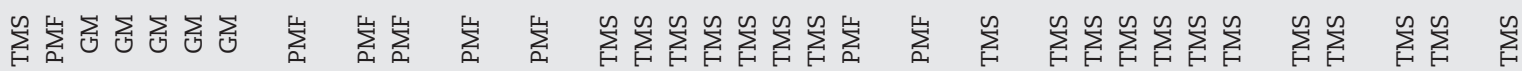

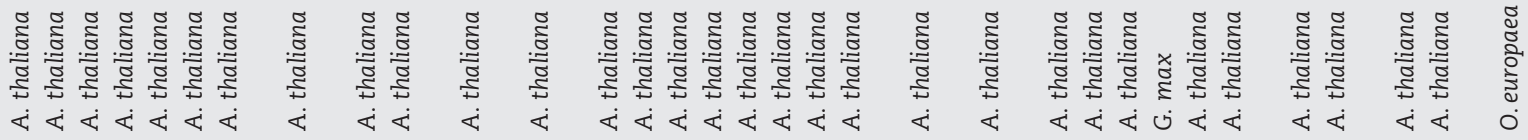

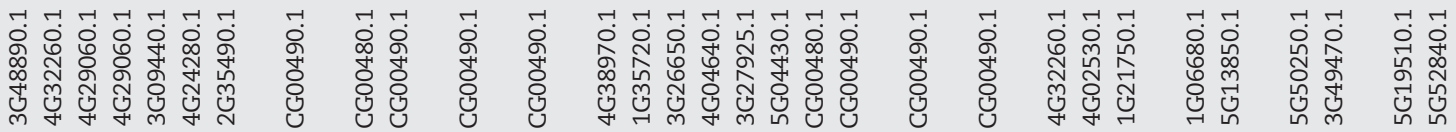

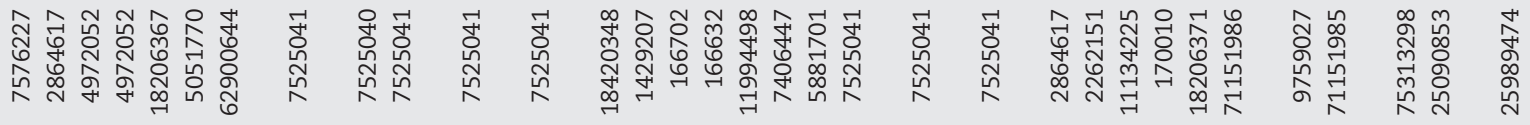
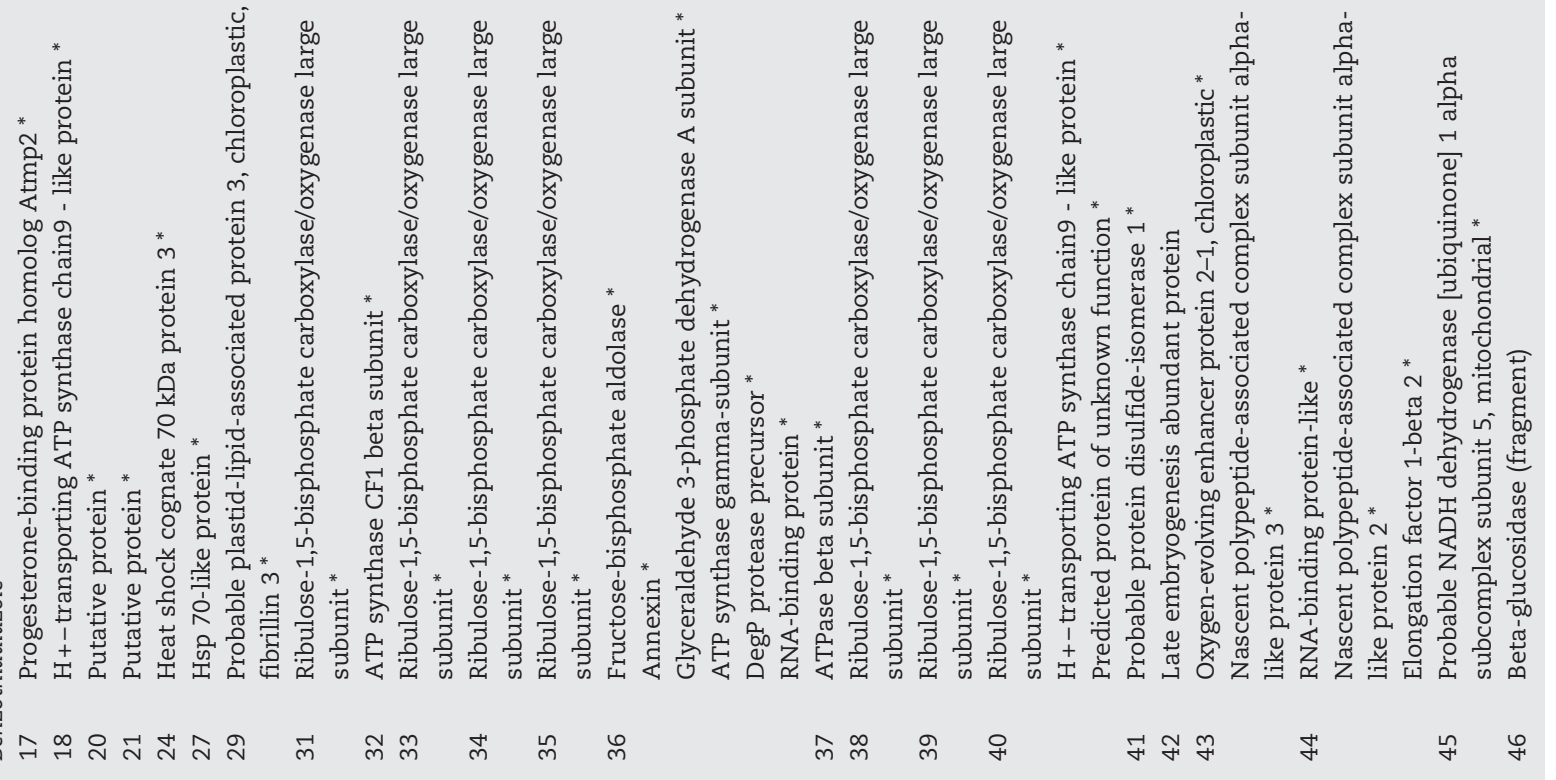


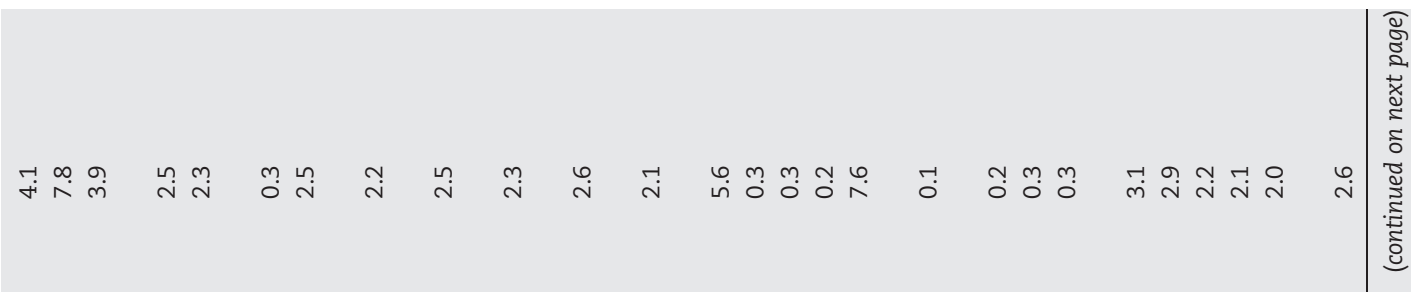

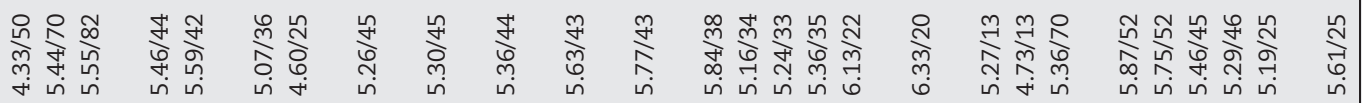

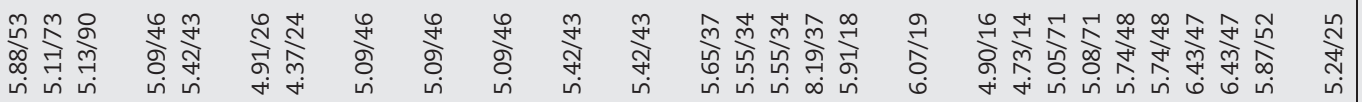

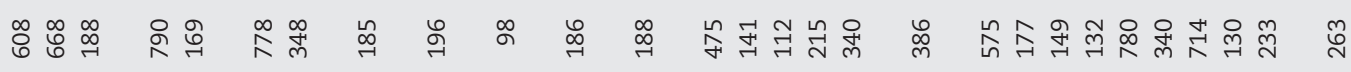

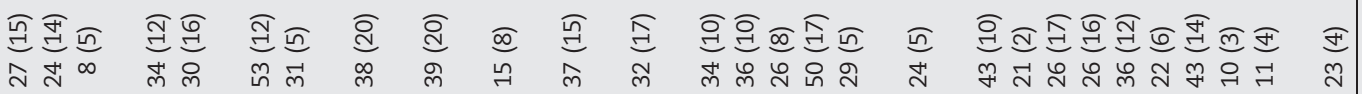

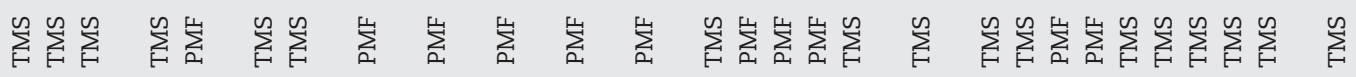

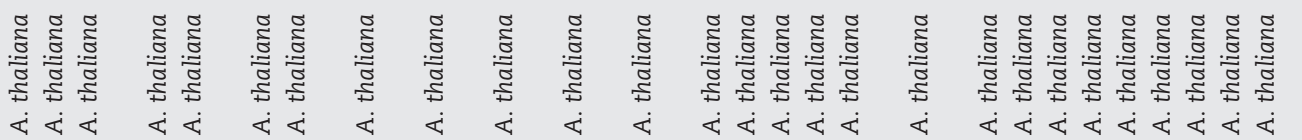

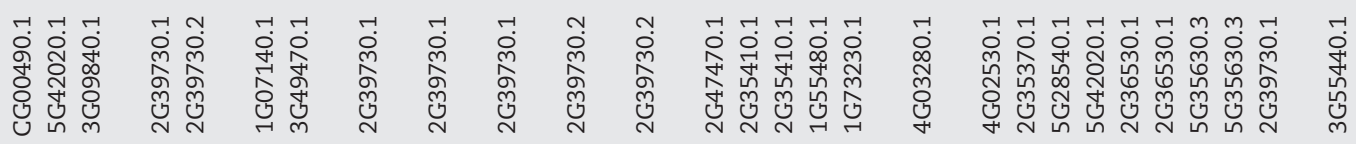

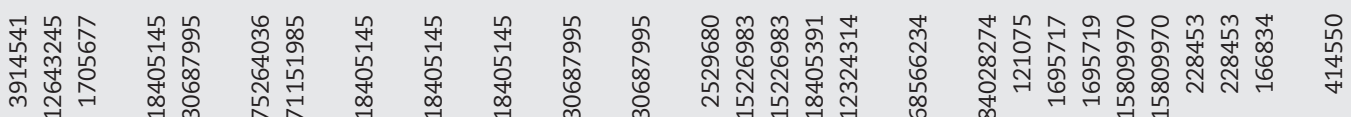

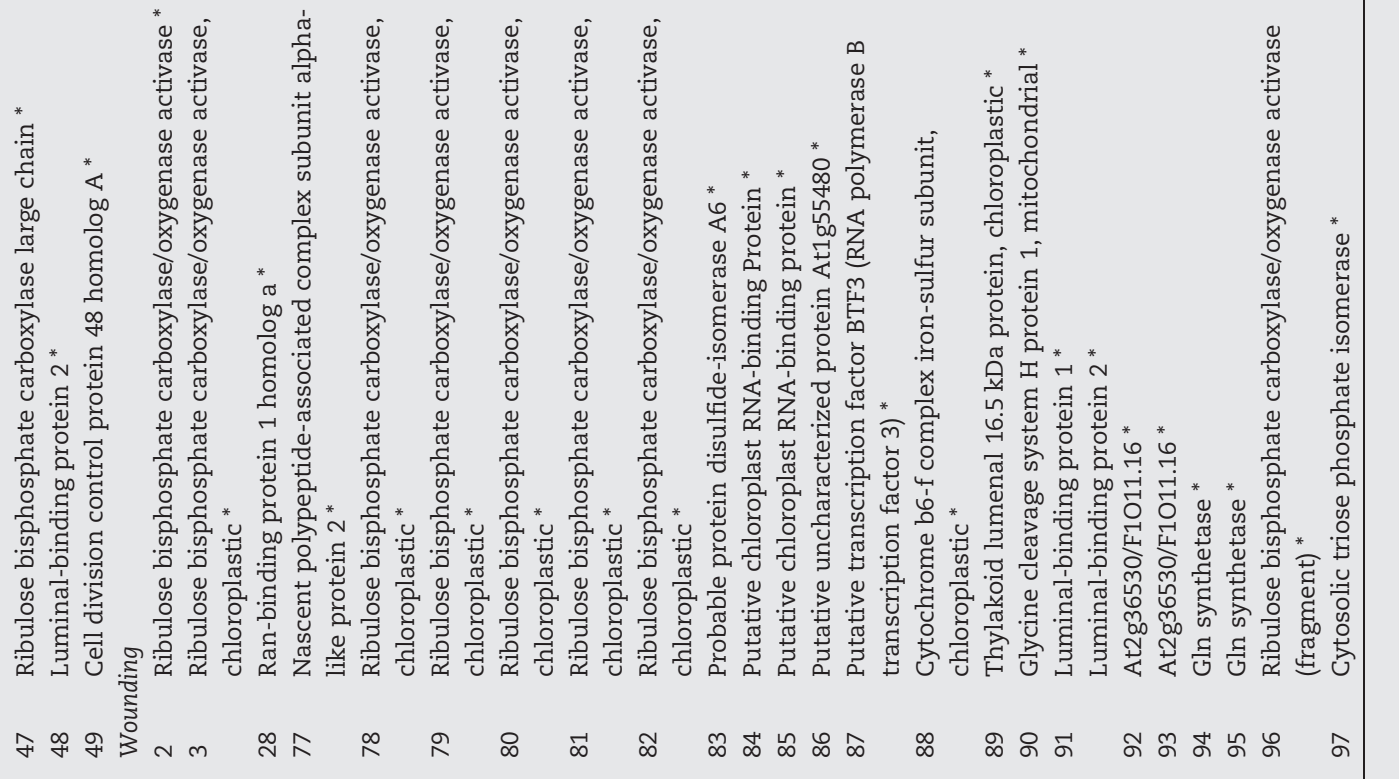




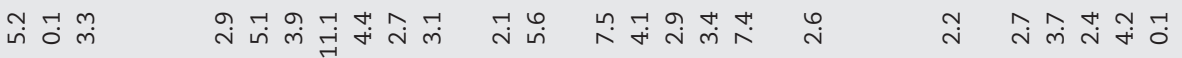

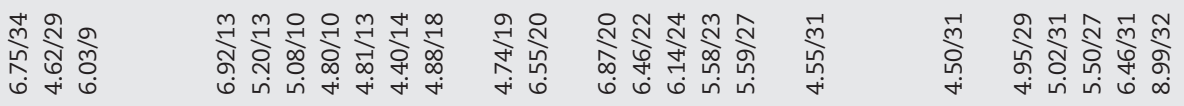

ल

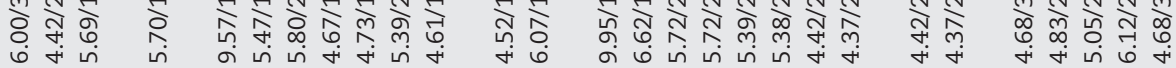

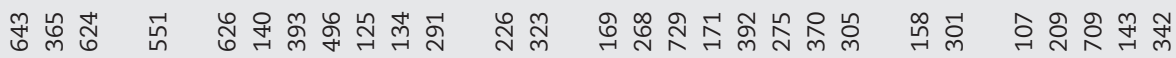

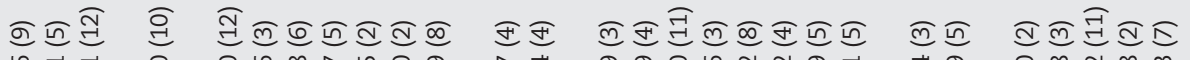

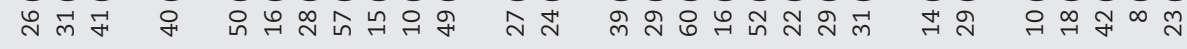
$\sum_{i}^{\infty} \sum_{i=1}^{\infty} \sum_{i=1}^{\infty} \sum_{i=1}^{\infty} \sum_{i=1}^{\infty} \sum_{i=1}^{\infty} \sum_{i=1}^{\infty} \sum_{i=1}^{\infty} \sum_{i=1}^{\infty} \sum_{i=1}^{\infty} \sum_{i=1}^{\infty} \sum_{i=1}^{\infty} \sum_{i=1}^{\infty} \sum_{i=1}^{\infty} \sum_{i=1}^{\infty} \sum_{i=1}^{\infty} \sum_{i=1}^{\infty} \sum_{i=1}^{\infty} \sum_{i=1}^{\infty} \sum_{i=1}^{\infty} \sum_{i=1}^{\infty}$

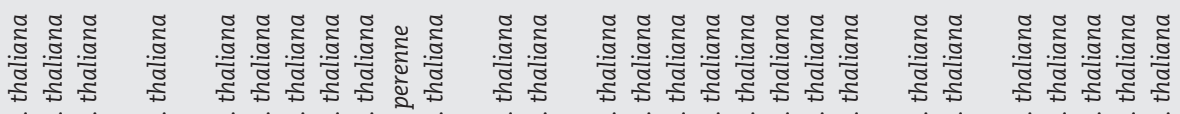
வिय

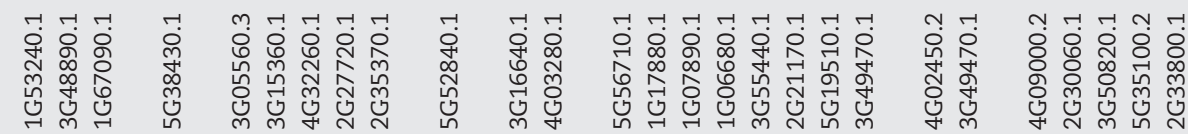

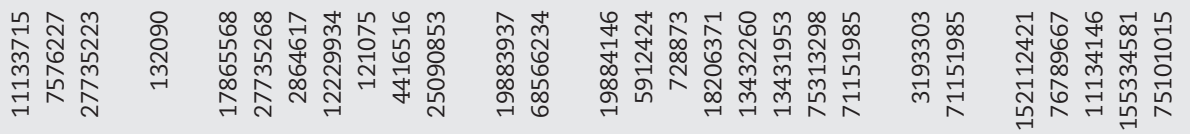


thioredoxins are small ubiquitous redox proteins encoded by large gene families [57], which are involved in regulation of Calvin cycle enzymes or function as hydrogen donors for antioxidant enzymes [58]. Peptidyl-prolyl cis-trans isomerase belongs to the large family of ciclophilins, accounting for 29 genes in Arabidopsis. Although their primary function is to assist protein folding [59], they have been recently reported being induced in response to various abiotic and biotic stresses [60]. Arabidopsis cyclophilin ROC1 has been also demonstrated to induce the self-cleavage of the product of the avirulence gene AvrRpt2 from P. syringae, thus contributing to plant innate immunity [61]. Another phosphoprotein with a function related to protection from stress is Atmp2 (spot 17), whose abundance was decreased after MV treatment, whereas was strongly increased following chitosan and benzothiadiazole treatment.

Methy viologen administration also determined an increased amount of phosphoproteins involved in protein synthesis. In particular, augmented levels were observed for phosphorylated Ran-binding protein 1 (spot 71), 60S ribosomal protein L31-3 (RPL31C) (spot 60), 60S ribosomal protein L22-2 (RPL22B) (spot 51) and 605 acidic ribosomal protein P2-2 (RPP2B) (spot 54). The first one has been already identified as up-regulated following chitosan treatment and down-regulated in wounded samples. On the other hand, RPL22B and RPP2B have also been reported to play functions related to plant defense, being RPL22B identified as an early-changed component upon elicitor treatments in Arabidopsis membrane phosphoproteome [30], whereas RPP2B acts as Arabidopsis determinant of Peronospora parasitica specific recognition through a gene-for-gene mechanism [62]. Other upregulated proteins were eukaryotic translation initiation factor 2 subunit $\beta$ (spot 75), nascent polypeptide-associated complex subunit $\alpha$-like protein 1 (spot 77) and 2 (spot 69), and BTF3b-like factor (spot 61). As far as the latter proteins, they were found with increased phosphorylation levels also in wounded leaves. Conversely, 30S ribosomal protein S5 (spot 74) was the only protein whose abundance decreased after MV treatment; it was previously identified as down-regulated nuclear protein present in cold-stressed Arabidopsis plants [63].

Other two up-regulated phosphoproteins whose function has been related to cell signaling were 14-3-3 protein GF14 $x$ isoform (spot 70) and calreticulin (spot 76). Highly conserved 14-3-3 proteins are regulatory proteins [64] that bind to a number of phosphorylated target proteins, thereby modifying their activity, localization or interaction [65]. In plants, 14-3-3s are involved in the regulation of fundamental processes [66], together with the response to various stresses. In fact, it has been shown that transcripts of specific 14-3-3 isoforms are induced upon abiotic/biotic stresses $[67,68]$ or pathogen challenge $[68,69]$. Furthermore, it has been shown that GF14 $\lambda$ interacts with APX3 [70] and its over-expression in Arabidopsis increases drought stress tolerance [71]. Different 14-3-3 interacting proteins involved in response to stress or defense have been identified, which confer resistance to virus and fungal pathogens [72-74]. Recently, GF14 $\lambda$ has been identified as a responsive phosphoprotein in a study on Arabidopsis proteome alterations upon P. syringae challenge [46]. On the other hand, calreticulin (CRT) is a ER-resident $\mathrm{Ca}^{2+}$-binding protein that plays an important role in $\mathrm{Ca}^{2+}$ signaling and protein folding. Plant CRTs have various properties that differ from their animal counterparts [75]. Endogenous basal expression levels of both CRT mRNAs and proteins are up-regulated in response to a wide range of stimuli, such as cold, salts and exogenous phytohormones. Rice phosphorylated CRT was shown to be involved in signaling pathways leading to cold stress response $[76,77]$. CRT was also shown to be induced in response to pathogen attacks [78] and to be involved in tobacco plant defence against TMV infections [79], indicating its potential role in the activation of inducible resistance mechanisms. Other two up-regulated phosphoproteins that do not classify in the above-mentioned categories are pollen allergen Lol pVA (spot 56) and translationally controlled tumor protein homolog (spot 58). A proteomic study on Arabidopsis proteome modifications upon bacterial challenge identified the latter as involved in basal defense [46].

\section{Conclusions}

Reversible protein phosphorylation is a pivotal regulatory mechanism in eukaryotic cells and increasing evidence indicates that it plays a fundamental role also in plant response to biotic and abiotic stresses [8,31]. In this study, we have described the quantitative changes of phosphoproteins present in A. thaliana leaves after challenge with elicitors of plant basal defense (chitosan and benzothiadiazole), an inducer of oxidative stress (methyl viologen) as well as mechanical injury (wounding). This analysis relied on selective extraction of phosphoproteins by means of MOAC and their subsequent analysis by a combined 2D electrophoresis/MS approach, which revealed specific changes in modification patterns upon elicitation by different stressors. This investigation allowed to identify 75 differentially modified candidates, which were almost all described previously as being phosphorylated [24-31]. Several of the identified phosphoproteins were shared by different stresses, thereby suggesting a partial overlapping of the responsive pathways (Fig. 4). These findings are in good agreement with other emerging evidences suggesting that mechanisms by which plants respond to various environmental and biotic stresses are not independent, but rather are involved in networks of at least partially superimposed biochemical events $[1,7,80,81]$.

Identified phosphoproteins grouped in various functional classes, with most represented candidates involved in energetic/carbon metabolism and stress/defense response. In chitosan-treated samples, for example, a reduced phosphorylation of enzymes implicated in carbon metabolism, photosynthesis and photorespiration, i.e. GP3DH, MDH, RuBisCO activase and cytochrome $b_{6}-f$ complex Fe-S subunit, was observed. It is noteworthy that Jones and coworkers already reported that Arabidopsis key metabolic enzymes, such as GP3DH and MDH, result PAMP-responsive and down-regulated following plant interaction with P. syringae [46]. This finding is in fairly good accordance with the observed down-regulation of primary carbon metabolism transcripts during basal defense [82]. In fact, it has been proposed that chloroplasts may be key players in plant defense and a loss of photosystem functionality can lead to ROS overproduction and to a decreased sugar availability to pathogens [83]. These findings may suggest that the observed quantitative changes in these phosphoproteins should reflect transcriptional phenomena more than being related to an augmented phosphorylation of a specific class of 


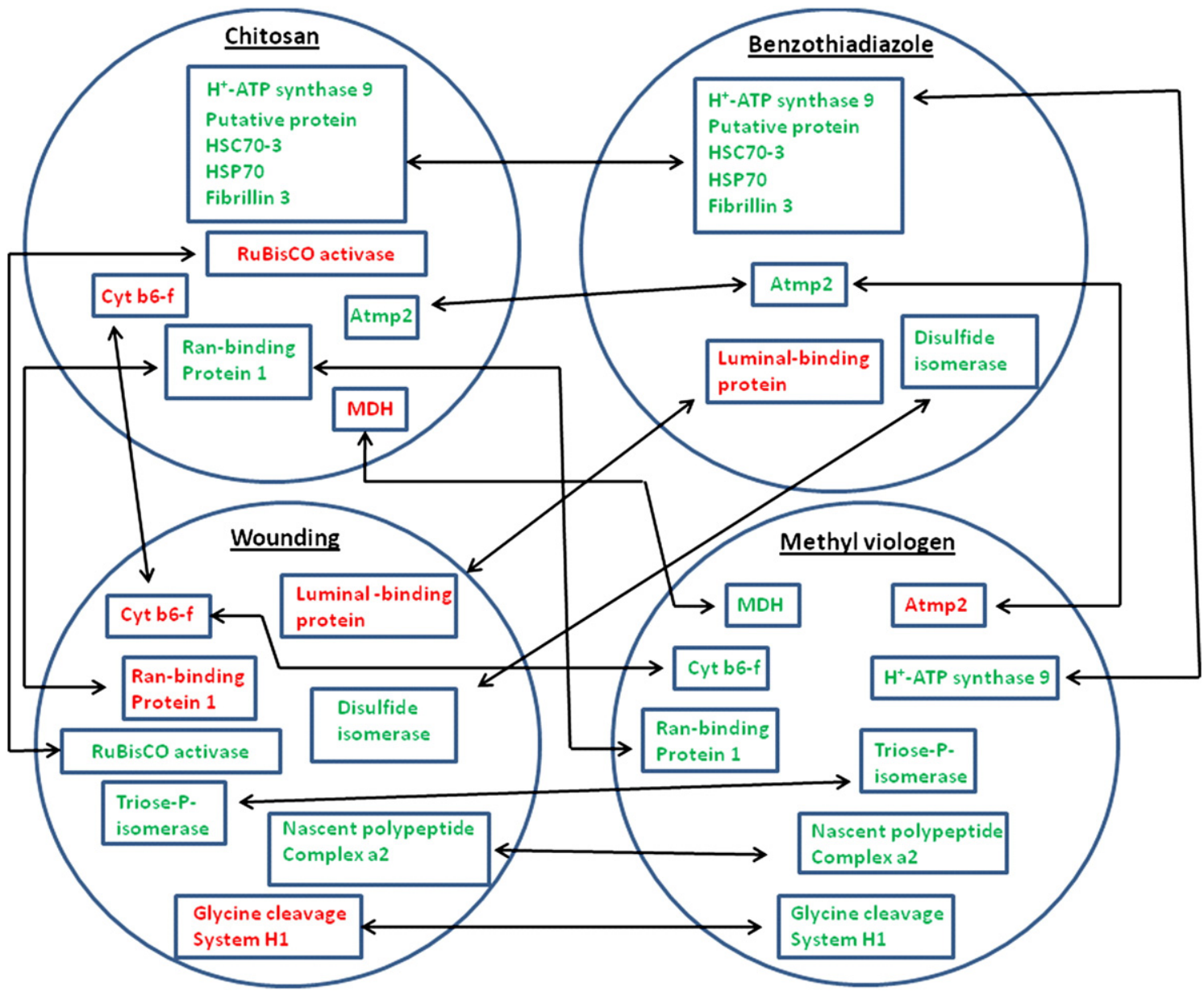

Fig. 4 - Common phosphoproteins changing their quantitative levels after treatment with elicitors of plant basal defence (chitosan and benzothiadiazole), mechanical injury (wounding) and an inducer of oxidative stress (methyl viologen). In green and red are reported phosphoproteins that increased and decreased their levels, respectively.

enzymes. Some of the metabolic enzymes having a reduced modification after chitosan treatment also showed a variable phosphorylation following other stresses, i.e. wounding (RuBisCO activase, cytochrome $b_{6}-\mathrm{f}$ complex Fe-S subunit) or methyl viologen ( $\mathrm{MDH}$, cytochrome $b_{6}-\mathrm{f}$ complex Fe-S subunit) (Fig. 4). In general, a comparison of the changes associated with the different stressors suggests that down-regulation of enzymes involved in carbon metabolism can be considered as specific for basal defense response to pathogens.

As far as proteins involved in protection from stress or defense responses, a number were found to be regulated by more than one stress. Phosphorylated HSC70s and HSP70s, for example, were identified both in chitosan- and benzothiadiazole-treated samples as strongly up-regulated species, whereas their levels apparently were not influenced by wounding or MV (Fig. 4). In a recent paper, it has been shown that Arabidopsis HSC70 chaperones interact with Sgt1, a conserved protein in eukaryotes, which participates into diverse signaling processes mediated by protein-protein interactions [84]. Thus, HSC70 binding to Sgt1 should act as a molecular switch for the response to different stresses, since it has been demonstrated that mutations in Sgt1 and HSC70 genes, altering proteins association, disabled basal and R-mediated resistance and increased heat shock tolerance [84]. In this contest, HSC70-3 phosphorylation may regulate this interaction. Previous studies demonstrated that HSC70-2 and 4 levels increased upon bacterial challenge [84], whereas we observed that chitosan determined up-regulation of the HSC703 isoform. Thus, our data seem to confirm that HSC70 chaperones may function as cross points between different stresses and suggest that the specificity of response towards various pathogens should be mediated by diverse HSC70 isoforms. A similarity in the modification profiles of chitosan and benzothiadiazole-treated plants was also highlighted by the common increased phosphorylation observed for fibrillin 3, a putative protein, Atmp2 as well as ATPase chain 9 (Fig. 4). Depending on treatment, quantitative differences between elicitors were measured. Changes in the latter two proteins were also observed following MV treatment (Fig. 4). Still regarding proteins related to stress/defense response, a similar trend was observed after MV challenge and wounding for phosphorylated chaperone luminal-binding protein [50] and stress-responsive nascent polypeptide-associated complex subunit $\alpha$-like protein [51] (Fig. 4), thus suggesting a regulation of common pathways in response to these stresses. 
Among the various proteins involved in RNA metabolism identified in this study, phosphorylated Ran-binding protein 1 increased following chitosan and methyl viologen treatment, whereas decreased after wounding (Fig. 4). This protein is a component of the Ran-GTPase-mediated mRNA/miRNA export from nucleus. Emerging evidences support the occurrence in plants of post-transcriptional gene regulation by miRNA and siRNA in response to pathogen and oxidative stresses [85]. Thus, phosphorylated Ran-binding protein 1 should act in these processes.

Peculiar phosphoproteins responsible for response pathways to specific stresses were also identified in this work. This was evident for MV-challenged plants, where up-regulated proteins directly involved in ROS detoxification were identified, such as APX1 and thioredoxin M-type 4. Conversely, protein disulfide-isomerase A6 was identified as strongly modified only in samples from wounded leaves. Interestingly, members of this protein family are involved in ER stress or unfolded protein response, which have also been implicated in pathogen response. Its identification may suggest the implication of related mechanisms also in the response to wounding.

In conclusion, this study has identified a number of candidate phosphoproteins regulated in planta by different elicitors or treatments mimicking pathogen attack or oxidative stress. Based on accumulated evidences regarding their function, some phosphorylated proteins are clearly involved in stress response mechanisms, whereas others seem to participate in pathways for which their relationship with defense responses is still relatively novel and/or largely incomplete. Data presented here also suggest a partial overlapping of the different response pathways and the occurrence of cross talk points. Future experiments focused on gel-free approaches for quantitative phosphoproteome analysis, extensive characterization of the modified amino acids in the phosphorylated proteins here reported, their functional analysis by site-directed mutagenesis or their use in reverse genetic approaches will be fundamental to validate the role of each identified protein/suggested pathway in plant basal defense responses.

Supplementary materials related to this article can be found online at doi:10.1016/j.jprot.2011.05.016.

\section{Acknowledgements}

BION 50 WG was kindly provided by Syngenta Crop Protection (Milan, Italy). This study was partially supported by grants from MIUR (PRIN2007_2007Y2WAE9_003) to MM and from Regione Campania (Rete di Spettrometria di Massa, RESMAC) to AS.

\section{R E F E R E N C E S}

[1] Valcu CM, Junqueira M, Shevchenko A, Schlink K. Comparative proteomic analysis of responses to pathogen infection and wounding in Fagus sylvatica. J Proteome Res 2009;8:4077-91.

[2] Heath MC. Non-host resistance and nonspecific plant defenses. Curr Opin Plant Biol 2000;3:315-9.
[3] Boller T, Felix G. A renaissance of elicitors: perception of microbe-associated molecular patterns and danger signals by pattern-recognition receptors. Annu Rev Plant Biol 2009;60: 379-406.

[4] Glowacki S, Macioszek VK, Konowics AK. R proteins as fundamentals of plant innate immunity. Cell Mol Biol Lett 2011;16:1-24.

[5] Grant M, Mansfield J. Early events in host-pathogen interactions. Curr Opin Plant Biol 1999;2:312-9.

[6] Sticher L, Mauch-Mani B, Metraux JB. Systemic acquired resistance. Annu Rev Phytopathol 1997;35:235-70.

[7] Mullineaux P, Ball L, Escobar C, Karpinska B, Creissen G, Karpinski S. Are diverse signaling pathways integrated in the regulation of Arabidopsis antioxidant defence gene expression in response to excess excitation energy? Phil Trans R Soc Lond B 2000;355:1531-40.

[8] Kersten B, Agrawal GK, Durek P, Neigenfind J, Schulze W, Walther D, et al. Plant phosphoproteomics: an update. Proteomics 2009;9:964-88.

[9] Metha A, Brasilero ACM, Souza DSL, Romano E, Campos MA, Grossi-de-Sà MF, et al. Plant-pathogen interactions: what is proteomics telling us? FEBS J 2008;275:3731-46.

[10] Iriti M, Faoro F. Chitosan as a MAMP, searching for a PRR. Plant Signal Behav 2009;4:66-8.

[11] Benhamou N, Bèlanger RR. Benzothiadiazole-mediated induced resistance to Fusarium oxysporum f. sp. radicis lycopersici in tomato. Plant Physiol 1998;118:1203-12.

[12] Leon J, Rojo E, Sànchez-Serrano JJ. Wound signaling in plants. J Exp Bot 2001;52:1-9.

[13] Kwon SI, Jeong YI, Lee HS, Kim JS, Cho KI, Allen RD, et al. Enhanced tolerance of transgenic tobacco plants expressing both superoxide dismutase and ascorbate peroxidase in chloroplast against methyl viologen oxidative stress. Plant Cell Environ 2002;25:873-82.

[14] Hadwiger LA, Beckam JM. Chitosan as a component of pea-Fusarium solani interactions. Plant Physiol 1980;66:205-11.

[15] Bellincampi D, Dipierro N, Salvi G, Cervone F, De Lorenzo G. Extracellular $\mathrm{H}_{2} \mathrm{O}_{2}$ induced by oligogalacturonides is not involved in the inhibition of the auxin-regulated rolB gene expression in tobacco leaf explants. Plant Physiol 2000;122:1379-85.

[16] Rocco M, D'Ambrosio C, Arena S, Faurobert M, Scaloni A, Marra M. Proteomic analysis of tomato fruits from two ecotypes during ripening. Proteomics 2006;6:3781-91.

[17] Röhrig H, Colby T, Schimdt J, Harzen A, Facchinelli F, Bartels D. Analysis of desiccation-induced candidate phosphoproteins from Craterostigma plantagineum isolated with a modified metal oxide affinity chromatography procedure. Proteomics 2008;8: 3548-60.

[18] Ramagli LS, Rodriguez LV. Quantitation of microgram amounts of protein in two-dimensional polyacrylamide gel electrophoresis sample buffer. Electrophoresis 1985;6:559-63.

[19] Talamo F, D'Ambrosio C, Arena S, Del Vecchio P, Ledda L, Zehender G, et al. Proteins from bovine tissues and biological fluids: defining a reference electrophoresis map for liver, kidney, muscle, plasma and red blood cells. Proteomics 2003;3:440-60.

[20] Bernardini G, Renzone G, Comanducci M, Mini R, Arena S, D'Ambrosio C, et al. Proteome analysis of Neisseria meningitidis serogroup A. Proteomics 2004;4:2893-926.

[21] Scippa GS, Rocco M, Ialicicco M, Trupiano D, Viscosi V, Di Michele M, et al. The proteome of lentil (Lens culinaris Medik.) seeds: discriminating between landraces. Electrophoresis 2010;31:497-506.

[22] Qian WJ, Liu T, Monroe ME, Strittmatter EF, Jacobs JM, Kangas LJ, et al. Probability-based evaluation of peptide and protein identification from tandem mass spectrometry and SEQUEST analysis: the human proteome. J Proteome Res 2005;4:53-62.

[23] Noctor G, Foyer CH. Ascorbate and glutathione: keeping active oxygen under control. Annu Rev Plant Physiol Plant Mol Biol 1998;49:249-79. 
[24] Nakagami H, Sugiyama N, Mochida K, Daudi A, Yoshida Y, Toyoda T, et al. Large-scale comparative phosphoproteomics identifies conserved phosphorylation sites in plants. Plant Physiol 2010;153:1161-74.

[25] Sugiyama N, Nakagami H, Mochida K, Daudi A, Tomita M, Shirasu K, et al. Large-scale phosphorylation mapping reveals the extent of tyrosine phosphorylation in Arabidopsis. Mol Syst Biol 2008;4:193.

[26] Reiland S, Messerli G, Baerenfaller K, Gerrits B, Endler A, Grossmann J, et al. Large-scale Arabidopsis phosphoproteome profiling reveals novel chloroplast kinase substrates and phosphorylation networks. Plant Physiol 2009;150:889-903.

[27] Chitteti BR, Peng Z. Proteome and phosphoproteome dynamic change during cell dedifferentiation in Arabidopsis. Proteomics 2007;7:1473-500.

[28] Hsu JL, Wang L-Y, Wang S-Y, Lin C-H, Ho K-C, Shi F-K, et al. Functional phosphoproteomic profiling of phosphorylation sites in membrane fractions of salt-stressed Arabidopsis thaliana. Proteome Sci 2009;7:42-58.

[29] Kwon SJ, Choi EY, Seo JB, Park OK. Isolation of the Arabidopsis phosphoproteome using a biotin-tagging approach. Mol Cells 2007;24:268-75.

[30] Benschop JJ, Mohammed S, O'Flaherty M, Heck AJR, Slijper M, Menke FLH. Quantitative phosphoproteomics of early elicitor signaling in Arabidopsis. Mol Cell Proteomics 2007;6:1198-214.

[31] Jones AME, Bennett MH, Mansfield JW, Grant M. Analysis of the defence phosphoproteome of Arabidopsis thaliana using differential mass tagging. Proteomics 2006;6:4155-65.

[32] Portis Jr AR. Rubisco activase-Rubisco's catalytic chaperone. Photosynth Res 2003;75:11-27.

[33] Cotelle V, Meek SE, Provan F, Milne FC, Morrice N, MacKintosh C. 14-3-3s regulate global cleavage of their diverse binding partners in sugar-starved Arabidopsis cells. EMBO J 2000;19:2869-76.

[34] Bustos DM, Bustamante CA, Iglesias AA. Involvement of non-phosphorylating gliceraldehyde-3-phosphate dehydrogenase in response to oxidative stress. J Plant Physiol 2008;165:456-61.

[35] Brkljacic J, Zhao Q Meier I. WWP-domain proteins mimic the activity of the HSC70-1chaperone in preventing mistargeting of Ran-Gap1-anchoring protein WIT1. Plant Physiol 2009;151: 142-54.

[36] Dufresne PJ, Thivierge K, Cotton S, Beauchemin C, Ide C, Ubalijoro E, et al. Heat shock 70 protein interaction with turnip mosaic virus RNA-dependent RNA polymerase within virus-induced membrane vescicles. Virology 2008;374:217-27.

[37] Fedoroff NV. RNA-binding proteins in plants: the tip of an iceberg? Curr Opin Plant Biol 2002;5:452-9.

[38] Giacomelli L, Rudella A, van Wijk KJ. High light response of the thylakoid proteome in Arabidopsis wild type and the ascorbate deficient mutant vtc2-2. A comparative proteomic study. Plant Physiol 2006;141:685-701.

[39] Haizel T, Merkle T, Pay A, Fejes E, Nagy F. Characterization of proteins that interact with the GTP-bound form of the regulatory GTPase Ran in Arabidopsis. Plant J 1997;11:93-103.

[40] Chinnusamy V, Gong Z, Zhu JK. Nuclear RNA export and its importance in abiotic stress responses of plants. Curr Top Microbiol Immunol 2008;326:235-55.

[41] Peltier JB, Yttemberg AJ, Sunt Q, van Wijk KJ. New functions of the thylakoid membrane proteome of Arabidopsis thaliana revealed by a simple, fast and versatile fractionation strategy. J Biol Chem 2004;279:49367-83.

[42] Gallois JL, Guyon-Debast A, Lécrueuil A, Vezon D, Carpentier $\mathrm{V}$, Bonhorme S, et al. The Arabidopsis proteasome RPT5 subunits are essential for gametophyte development and show accession-dependent redundancy. Plant Cell 2009;21: 442-59.

[43] Hatsugai N, Iwasaki S, Tamura K, Kondo M, Fuji K, Ogasawara $\mathrm{K}$, et al. A novel membrane fusion-mediated plant immunity against bacterial pathogens. Genes Dev 2009;23:2496-506.
[44] Peterman TK, Ohol YM, McReinolds LJ, Luna EJ. Patellin1, a novel Sec14-like protein, localizes to the cell plate and binds phosphoinositides. Plant Physiol 2004;136:3080-94.

[45] Youssef A, Laizet Y, Block MA, Marechal E, Alcaraz J-P, Larson $\mathrm{T}$, et al. Plant-lipid associated fibrillin proteins condition jasmonate production under photosynthetic stress. Plant J 2010;61:436-45.

[46] Jones E, Thomas V, Bennett MH, Mansfield J, Grant M. Modifications to the Arabidopsis defense proteome occur prior to significant transcriptional change in response to inoculation with Pseudomonas syringae. Plant Physiol 2006;132:1603-20.

[47] Lee H, Guo Y, Ohta M, Xiong L, Stevenson B, Zhu JK. LOS2, a genetic locus required for cold-responsive gene transcription encodes a bi-functional enolase. EMBO J 2002;21:2692-702.

[48] Urade $R$. The endoplasmic reticulum stress signaling pathways in plants. Biofactors 2009;35:326-31.

[49] Vitale A, Ceriotti A. Protein quality control mechanisms and protein storage in the endoplasmic reticulum. A conflict of interest? Plant Physiol 2004;136:3420-6.

[50] Slabas AR, Ndimba B, Simon WJ, Chivasa S. Proteomic analysis of the Arabidopsis cell wall reveals unexpected proteins with new cellular locations. Biochem Soc Trans 2004;32:524-8.

[51] Yan S, Tang Z, Su W, Sun W. Proteomic analysis of salt-stress-responsive proteins in rice root. Proteomics 2005;5:235-44.

[52] Jiang Y, Yang B, Harrie NS, Dehyolos HM. Comparative proteomic analysis of $\mathrm{NaCl}$ stress-responsive proteins in Arabidopsis roots. J Exp Bot 2007;58:3591-607.

[53] Alvarez S, Zhu M, Chen S. Proteomics of Arabidopsis redox proteins in response to mehyl jasmonate. J Proteomics 2009;73:30-40.

[54] Taler D, Galperin M, Benjamin I, Cohen Y, Kenigsbuch D. Plant $\mathrm{R}$ genes that encode photorespiratory enzymes confer resistance against disease. Plant Cell 2004;16:172-84.

[55] Chew O, Whelan J, Millar HJ. Molecular definition of the ascorbate-glutathione cycle in Arabidopsis mitochondria reveals dual targeting of antioxidant defenses in plants. Biol Chem 2003;278:46869-77.

[56] Davletova S, Rizhsky L, Liang H, Zhong S, Oliver DJ, Coutu J, et al. Cytosolic ascorbate peroxidase is a central component of the reactive oxygen gene network of Arabidopsis. Plant Cell 2005;17:268-81.

[57] Buchanan BB, Balmer Y. Redox regulation: a broadening horizon. Annu Rev Plant Biol 2005;56:187-220.

[58] Marri L, Zaffagnini M, Collin V, Issakidis-Bourguet E, Lemaire SD, Pupillo P, et al. Prompt and easy activation by specific thioredoxins of calvin cycle enzymes of Arabidopsis thaliana associated in the GAPDH/CP12/PRK supramolecular complex. Mol Plant 2009;2:259-69.

[59] Schiene-Fischer C, Yu C. Receptor accessory folding helper enzymes: the functional role of peptidyl prolyl cis/trans isomerase. FEBS Lett 2001;495:1-6.

[60] Sekhar K, Priyanka B, Reddy VD, Rao KV. Isolation and characterization of a pigeonpea cyclophilin (CcCYP) gene, and its over-expression in Arabidopsis confers multiple abiotic stress tolerance. Plant Cell Environ 2010;33:1324-38.

[61] Aumüller T, Jaheris G, Fischer G, Schiene-Fischer C. Role of prolyl cis/trans isomers in cyclophilin-assisted Pseudomonas syringae AvrRpt2 protease activation. Biochemistry 2010;49: 1042-52.

[62] Sinapidou E, Williams K, Nott L, Bahkt, Tor M, Brute I, et al. Two TIR:NB:LRR genes are required to specify resistance to Peronospora parasitica isolate Cala2 in Arabidopsis. Plant J 2004;38:898-909.

[63] Bae MS, Cho EJ, Choi EY, Park OK. Analysis of the Arabidopsis nuclear proteome and its response to cold stress. Plant J 2003;36:652-63.

[64] Ferl RJ. 14-3-3 proteins and signal transduction. Annu Rev Plant Physiol Plant Mol Biol 1996;47:49-73. 
[65] Sehnke PC, Delille JM, Ferl RJ. Consummating signal transduction: the role of 14-3-3 proteins in the completion of signal induced-transitions in protein activity. Plant Cell 2002;14:39-54.

[66] Aducci P, Camoni L, Marra M, Visconti S. From cytosol to organelles: 14-3-3 proteins as multifunctional regulators of plant cell. IUBMB Life 2002;53:49-55.

[67] Roberts MR, Salinas J, Collinge DB. 14-3-3 proteins and the response to abiotic and biotic stress. Plant Mol Biol 2002;50: 1031-9.

[68] Chen F, Li Q, Sun L, He Z. The rice 14-3-3 gene family and its involvement in response to biotic and abiotic stress. DNA Res 2002;13:53-63.

[69] Brandt J, Thordal-Christensen H, Vad K, Gregersen PL, Collinge DB. A pathogen-induced gene of barley encodes a protein showing high similarity to a protein-kinase regulator. Plant J 1992;2:815-20.

[70] Zhang H, Wang J, Nickel U, Allen RD, Goodman H. Cloning and expression of an Arabidopsis gene encoding a putative peroxisomal ascorbate peroxidase. Plant Mol Biol 1997;34: 967-71.

[71] Yan J, He C, Wang J, Mao Z, Holaday SA, Allen RD, et al. Overexpression of the Arabidopsis 14-3-3 protein GF14 lambda in cotton leads to a "stay-green" phenotype and improves stress tolerance under moderate drought conditions. Plant Cell Physiol 2004;45:1007-14.

[72] Elmayan T, Fromentin J, Riondet C, Alcaraz G, Blein JP, Simon-Plas F. Regulation of reactive oxygen species production by a 14-3-3 protein in elicited tobacco cells. Plant Cell Env 2007;30:722-32.

[73] Konagaya K, Matsushita Y, Kasahara M, Nyunoya H. Members of 14-3-3 protein isoforms interacting with the resistance gene product $\mathrm{N}$ and the elicitor of tobacco mosaic virus. J Gen Plant Pathol 2004;70:221-31.

[74] Yang X, Wang W, Coleman M, Orgil U, Feng J, Ma X, et al. Arabidopsis 14-3-3 lambda is a positive regulator of RPW8-mediated disease resistance. Plant J 2009;60:539-50.

[75] Jia XY, He LH, Jing RL, Li RZ. Calreticulin: conserved protein and diverse function in plants. Physiol Plant 2009;136:127-38.
[76] Li Z, Onodera H, Ugaki M, Tanaka H, Komatsu S. Characterization of calreticulin as a phosphoprotein interacting with cold-induced protein kinase in rice. Biol Pharm Bull 2003;26:256-61.

[77] Komatsu S, Yang G, Khan M, Onodera H, Toki S, Yamaguchi M. Over-expression of calcium-dependent protein kinase 13 and calreticulin interacting protein 1 confers cold tolerance on rice plants. Mol Genet Genomics 2007;277:713-23.

[78] Jelitto-Van Dooren EP, Vidal S, Denecke J. Anticipating endoplasmic reticulum stress. A novel early response before pathogenesis-related gene induction. Plant Cell 1999;11: 1935-44.

[79] Chen MH, Tain GV, Gafni Y, Citovsky V. Effects of calreticulin on viral cell-cell movement. Plant Physiol 2005:1866-76.

[80] Bowler C, Fluhr R. The role of calcium and activated oxygens as signals for controlling cross-tolerance of cross-tolerance. Trends Plant Sci 2000;5:241-6.

[81] Orsini F, Cascone P, De Pascale S, Barbieri G, Corrado G, Rao R, et al. Systemin-dependent salinity tolerance in tomato: evidence for specific convergence of abiotic and biotic stress responses. Physiol Plant 2010;138:10-21.

[82] Truman W, de Torres Zabala M, Grant M. Type III effectors orchestrate a complex interplay between transcriptional networks to modify basal defense responses during pathogenesis and resistance. Plant J 2006;46:14-33.

[83] Zou J, Rodriguez-Zas S, Aldea M, Li M, Zhu J, Gonzalez OD, et al. Expression profiling soybean response to Pseudomonas syringae reveals new defense-related genes and rapid HR-specific downregulation of photosynthesis. Mol Plant Microbe Interact 2005;18:1161-74.

[84] Nöel LD, Cagna G, Stuttmann J, Wirthmuller L, Betsuyaku S, Witte C-P, et al. Interaction between SGT1 and cytosolic/nuclear HSC70 chaperones regulates Arabidopsis immune response. Plant Cell 2007;19:4061-76.

[85] Shukla LI, Chinnusamy V, Sunkar R. The role of microRNAs and other endogenous small RNAs in plant stress responses. Biochim Biophys Acta 2008:743-8. 